\title{
Hydrogen Embrittlement Understood
}

\author{
IAN M. ROBERTSON, P. SOFRONIS, A. NAGAO, M.L. MARTIN, S. WANG, \\ D.W. GROSS, and K.E. NYGREN
}

IAN M. ROBERTSON

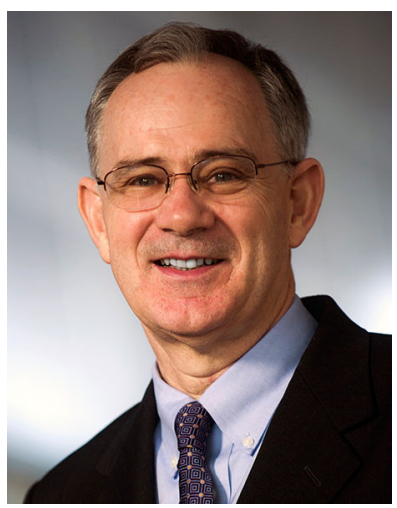

The connection between hydrogen-enhanced plasticity and the hydrogen-induced fracture mechanism and pathway is established through examination of the evolved microstructural state immediately beneath fracture surfaces including voids, "quasi-cleavage," and intergranular surfaces. This leads to a new understanding of hydrogen embrittlement in which hydrogenenhanced plasticity processes accelerate the evolution of the microstructure, which establishes not only local high concentrations of hydrogen but also a local stress state. Together, these factors establish the fracture mechanism and pathway.

DOI: $10.1007 / \mathrm{s} 11661-015-2836-1$

(C) The Minerals, Metals \& Materials Society and ASM International 2015

\section{INTRODUCTION}

JOHNSON, in 1875 , launched the field of study of hydrogen embrittlement of metals with the publication

IAN M. ROBERTSON, Dean of the College of Engineering and a Professor, is with Department of Materials Science and Engineering and Department of Engineering Physics, University of Wisconsin Madison, Madison, WI 53706, and also with International Institute for Carbon-Neutral Energy Research (WPI-I2CNER), Kyushu University, 744 Motooka, Nishi-ku, Fukuoka, Fukuoka 819-0395, Japan. Contact e-mail: Ian.Robertson@wisc.edu P. SOFRONIS, James W. Bayne Professor, is with the Department of Mechanical Science and Engineering, University of Illinois at Urbana-Champaign, Urbana, IL 61801, and also with International Institute for Carbon-Neutral Energy Research (WPI-I2CNER), Kyushu University. A. NAGAO, Senior Researcher, is with International Institute for Carbon-Neutral Energy Research (WPI-I2CNER), Kyushu University, and also with Material Surface \& Interface Science Research Department, Steel Research Laboratory, JFE Steel Corporation, 1-1 Minamiwataridacho, Kawasaki-ku, Kawasaki, Kanagawa 210-0855, Japan. M.L. MARTIN, Humboldt Postdoctoral Fellow, is with Institut für Materialphysik, Georg-August-Universität Göttingen, FriedrichHund-Platz 1, 37077 Göttingen, Germany. S. WANG, Postdoctoral Fellow, is with International Institute for Carbon-Neutral Energy Research (WPI-I2CNER), Kyushu University, and also with Division of Materials Science and Engineering, Graduate School of Engineering, Hokkaido University, N-13, W-8, Sapporo, Hokkaido 060-8628, Japan. D.W. GROSS, and K.E. NYGREN, Graduate Students, are of his observations of the influence of immersing a piece of iron in different acids on the mechanical properties. ${ }^{[1]}$ $\mathrm{He}$ summarized the macroscale effect as: "After a few

with the Department of Materials Science and Engineering, University of Illinois at Urbana-Champaign, Urbana, IL 61801.

Ian M. Robertson is the Dean of the College of Engineering and a professor in Materials Science and Engineering as well as Engineering Physics at the University of Wisconsin-Madison. His research focuses on the use of the electron microscope as an experimental laboratory in which dynamic experiments can be conducted to reveal the atomistic processes responsible for the macroscopic response of a material. $\mathrm{He}$ has applied this technique to enhance our understanding of the reaction pathways and kinetics that occur during deformation, phase transformation, irradiation and hydrogen embrittlement of metallic materials. His insight to the mechanisms responsible for hydrogen embrittlement of metals was recognized by the Department of Energy in 1984 when he, along with Howard Birnbaum, received the DOE prize for Outstanding Scientific Accomplishment in Metallurgy and Ceramics. In 2011, he received the DOE EE Fuel Cell Program award for contributions to our understanding of mechanisms of hydrogen embrittlement. He was selected recently as the 2014 recipient of the ASM Edward DeMille Campbell Memorial Lectureship. He is the Editor-in-Chief of the review journal Current Opinion in Solid State and Materials Science.

Manuscript submitted January 17, 2015.

Article published online March 28, 2015 
minutes' immersion (half a minute will sometimes suffice) in strong hydrochloric or dilute sulfuric acid-a piece breaking after being bent once on itself, while before immersion it would bear bending on itself and back again two or three times before breaking." $\mathrm{He}$ further noted that "...evident to any one by the extraordinary decrease in toughness and breaking-strain of the iron so treated, and is all the more remarkable as it is not permanent, but only temporary in character, for with lapse of time the metal slowly regains its original toughness and strength." Although Johnson's description remains appropriate, it now has been shown to occur in most metals within a narrow temperature and strain rate range and is reversible if the hydrogen is removed. These signature dependencies of hydrogen embrittlement are important to remember as any approach to discern the physical mechanism must demonstrate them. Furthermore, the mechanism must be universal as it would be extremely unfortunate if it was not broadly applicable across a particular class of hydrogen-induced failures. Of course, it is recognized that there is more than one class and more than one mechanism may exist. For example, the hydride formation and cleavage mechanism certainly operates in Group Vb pure metals and their alloys, as well as in titanium and zirconium. ${ }^{[2,3]}$ However, even in these systems, other mechanisms may operate, but not necessarily dominate the response. ${ }^{[4]}$ Despite the extensive database of hydrogen-induced failures of metallic structures, the fundamental mechanisms remain in debate; for details on hydrogen effects on mechanical properties; for details the reader is referred to recent conference proceedings, book chapters, and references therein. ${ }^{[5,6]}$

Discovery of the underlying fundamental mechanisms of hydrogen embrittlement is a complex multi-faceted challenge that requires knowledge of the hydrogen source, and how hydrogen molecules interact with the oxide on the metal surface, then how hydrogen enters the base metal, diffuses through the lattice or along grain boundaries, interacts with and is trapped by microstructural features, modifies the properties of metals, moves with mobile dislocations, and results in ductile, "quasi-cleavage," and intergranular fracture modes. The emphasis of this manuscript is on the modifications to properties of dislocations and deformation mechanisms by hydrogen, hydrogen-defect interactions, and how these link to the hydrogen-induced fracture mode and path. Specifically, the emphasis of this manuscript is captured in two assertive statements made by Beachem in 1972, ${ }^{[7]}$ namely, that the "hydrogen-steel interaction appears to be an easing of dislocation motion or generation, or both," and "fracture modes operate depending upon the microstructure." Evidence supporting the former has been provided primarily by the deformation experiments performed in an electron microscope equipped with an environmental cell: ${ }^{[8,9]}$ key results of this work are described in detail later. Experimental evidence supporting a correlation between the microstructure and the fracture mode has been lacking. However, progress in establishing this linkage has been enabled through recent advances in experimental tools and methods. For example, focused- ion beam machining affords the opportunity to extract a volume of material from a site-specific location, including ones on complex fracture surfaces for subsequent examination in a transmission electron microscope. ${ }^{[10]}$ This approach has been used to determine the microstructure that has evolved beneath different types of hydrogeninduced fracture surfaces including flat features on pipeline steels, [11] "quasi-cleavage" fracture surfaces on pipeline steels, ${ }^{[12]}$ microvoids, ${ }^{[13]}$ "quasi-cleavage" and intergranular surfaces in lath martensite steels, ${ }^{[13,14]}$ and intergranular facets in $\mathrm{Ni}^{[15]}$ and Fe. ${ }^{[16]}$ As detection of hydrogen at specific locations remains one of the outstanding issues in hydrogen-induced degradation of metals, it is inferred from observed responses. The remainder of this manuscript begins with a brief summary of the mechanisms that have been proposed to account for hydrogen embrittlement; a description of key experimental findings supporting hydrogen-enhanced dislocation motion; examination of evolved microstructure and its correlation to the fracture mechanism and pathway; and ends with discussion and conclusions.

\section{PROPOSED MECHANISMS}

Numerous mechanisms have been proposed to account for hydrogen embrittlement and these have been reviewed extensively. ${ }^{[17-19]}$ The proposed mechanisms include:

- High hydrogen pressure bubble or void; ${ }^{[20-22]}$

- Hydrogen-induced reduction in surface energy; ${ }^{[23,24]}$

- Hydrogen-enhanced dislocation ejection from the surface or near surface region; ${ }^{[17]}$

- Hydrogen-induced reduction in cohesive strength; ${ }^{[6,18,25-28]}$

- Hydrogen-enhanced localized plasticity; ${ }^{[7,9,29-31]}$

- Hydrogen- and deformation-assisted vacancy production; ${ }^{[32-34]}$

- Hydrogen-triggered ductile to brittle transition; ${ }^{[35,36]}$

- Hydride formation and cleavage; ${ }^{[2,3]}$

- Hydrogen- and strain-induced phase transformations, ${ }^{[37,38]}$ and

- Reactants and hydrogen. ${ }^{[39]}$

Of these possibilities, the operative ones depend on the material, the hydrogen charging conditions, and the loading. For example, the high pressure bubble mechanism is related to the precipitation of $\mathrm{H}_{2}$ and it occurs under high fugacity charging conditions. The hydride formation and cleavage mechanism operates in Group $\mathrm{Vb}$ pure metals and their alloys as well as in titanium and zirconium systems. ${ }^{[2,3]}$ It may operate in other metal systems under extreme hydrogen charging conditions. ${ }^{[40]}$ Of the others, the most commonly invoked are the hydrogen-enhanced decohesion and hydrogen-enhanced localized plasticity mechanisms; these are considered in more detail later. A new mechanism, the hydrogenenhanced plasticity mediated failure mechanism is introduced here.

Although some of the listed mechanisms can now be considered questionable or of little importance, at the time they were introduced each played a vital role in advancing the state of understanding of hydrogen embrittlement. For example, the magnitude of the 
reduction of the surface energy by hydrogen is negligible and when this is considered in conjunction with the plastic work of separation, the overall effect becomes inconsequential. The enhanced injection of dislocations from sources at or in close proximity to the surface is based on similarities of morphological features on fracture surfaces produced by liquid-metal and hydrogen and on the a posteriori interpretation of these features in terms of plasticity. ${ }^{[17]}$ However, recent studies using advanced characterization methods have shown that our knowledge of the microstructural evolution during different loading conditions, as well as the self-organization of dislocation structures, is incomplete. These observations have made a posteriori interpretation of evolved microstructure, and hence the derived mechanism, questionable. It has also been found that similar morphological features on fracture surfaces are not necessarily driven by the same underlying processes. ${ }^{[10-12,15,16,41]}$ Phase transformations certainly occur in some alloy systems in the presence of strain and hydrogen. ${ }^{[37,38,42-44]}$ However, the dilemma is in determining the role of the phase transformation in the hydrogen embrittlement process and in determining when it occurs. That is, is it a pre-requisite for hydrogen embrittlement or does it occur in association with the plasticity prior to or in association with crack nucleation and propagation? The hydrogen-triggered ductile-tobrittle transition mechanism, developed by Curtin and coworkers, is based on a finite-temperature coupled atomistic/discrete dislocation multi-scale method and large-scale molecular dynamics simulations of hydrogen processes at crack tips in $\mathrm{Ni}^{[35]}$ and $\mathrm{Fe}^{[36]}$ They reported the accumulation of a high concentration of hydrogen at the crack tip, which in the Ni case they compared to a nano-hydride. The formation of this nano-hydride caused a transition in the fracture mode from ductile to brittle by suppressing the emission of dislocations from the crack tip. A similar process was proposed to occur in Fe. However, experimentally it is found that dislocation emission is associated with crack extension in $\mathrm{Ni}$ and $\mathrm{Fe}$ in the presence and absence of hydrogen and the fracture path is not along a cleavage plane in the metal or the associated hydride. These results raise questions about the viability of this mechanism. Furthermore, it remains to be shown that the approach, along with its constraints, is capable of emulating the key features of hydrogen embrittlement, namely the dependence on the strain rate and temperature and its independence of material crystal structure. It also makes the assumption that the rate-controlling step in hydrogen embrittlement is directly linked to crack tip processes propagating into a pristine matrix and any plasticity that occurs prior to the failure event is irrelevant. Finally, the attribution of vacancies as the responsible mechanism for failure is an interesting one. ${ }^{[45-47]}$ Vacancies are certainly generated by plastic processes and this generation may be facilitated and enhanced by the presence of hydrogen via a reduction in the formation energy. ${ }^{[48]}$ However, how these vacancies aggregate to account for the various fracture surface morphologies remains to be addressed. Also, it is not obvious that the accumulation of vacancies is necessarily

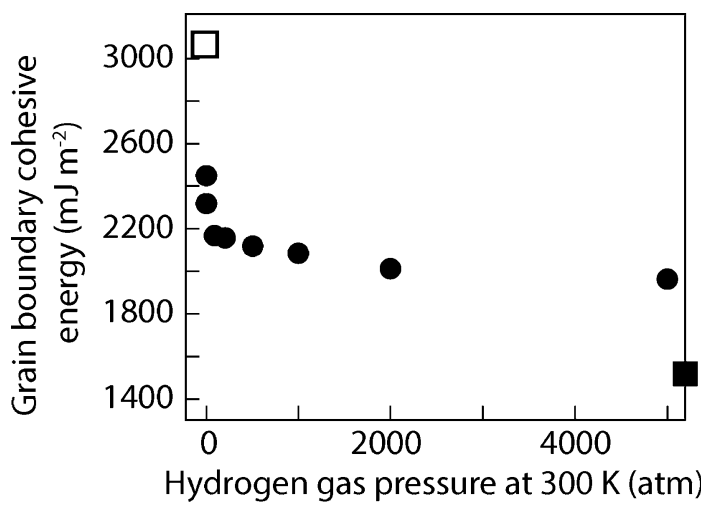

Fig. 1-Grain boundary cohesive energy as a function of hydrogen gas pressure for a $\sum 5(120)$ grain boundary in Fe. Open square- no hydrogen; filled square - gas pressure is $48,346 \mathrm{~atm}(5 \mathrm{GPa})$.

a reversible process if the materials are left at room temperature for an extended period of time.

The fundamental principle behind the hydrogenenhanced decohesion mechanism is that the presence of hydrogen in the lattice reduces the bond strength, and this leads to rupture at lower levels of stress. Computer simulation techniques have been used to explore the change in the bond strength due to the presence of hydrogen. ${ }^{[49-51]}$ For example, to determine how the cohesive strength of grain boundaries in $\mathrm{Fe}$ was reduced by the presence of hydrogen, Wang et al. ${ }^{[52]}$ used the parallel molecular dynamics code LAMMPS ${ }^{[53]}$ with a density functional theory based $\mathrm{Fe}-\mathrm{H}$ embedded atom method potential, ${ }^{[54,55]}$ updated to prevent unphysical $\mathrm{H}-\mathrm{H}$ aggregation, ${ }^{[36]}$ to describe the interatomic interactions. An example of Wang et al.'s results for a $\Sigma 5(120)$ grain boundary in Fe is shown in Figure 1. ${ }^{[52]}$ This plot shows how the cohesive strength of a grain boundary is reduced as a function of hydrogen content under equilibrium conditions (constant chemical potential). In this case, the hydrogen content is expressed in terms of the hydrogen gas charging pressure. The percentage reduction in grain boundary cohesive energy due to the presence of hydrogen is 30 pct at a pressure of $1000 \mathrm{~atm}(101.3 \mathrm{MPa}), 36$ pct at $5000 \mathrm{~atm}(506.5 \mathrm{MPa})$ and 54 pct at $48,346 \mathrm{~atm}(5 \mathrm{GPa})$; the latter is indicated by the filled square in Figure 1. Solanki et al. reported that the local $\mathrm{H}$ trapping limit at symmetric tilt grain boundaries in $\mathrm{Fe}$ was dependent on the boundary character. ${ }^{[56]}$ For example, it was 4.4 and 7 pct for a $\sum 53$ (720) and $\sum 17$ (410) symmetric tilt grain boundaries, respectively. The magnitude of the change in the cohesive strength increased with increasing percentage of hydrogen at the grain boundary. At the local hydrogen trapping limit for a $\sum 53$ (720) symmetric tilt grain boundary, the decrease in the cohesive strength was 78 pct. If these findings are correct and the calculations are consistent with that for other grain boundaries, it raises the question about the critical level of hydrogen needed to induce intergranular failure, as well as how this level can be achieved under the conditions associated with hydrogen-induced failure. Further studies are required to determine the magnitude of the hydrogen reduction in the cohesive strength of 


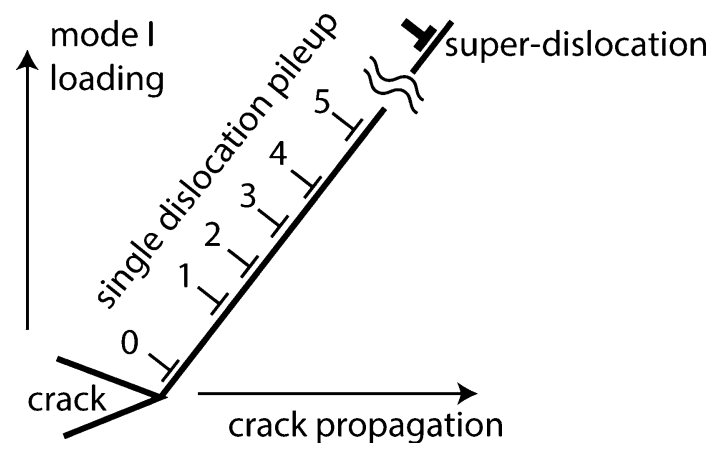

Fig. 2-Schematic of the dislocation-shielding geometry used in determination of the expression of the threshold stress intensity. Adapted from Ref. [60]. Reproduced with permission from Elsevier.

grain boundaries in other systems in which hydrogen is known to cause a transition in the failure mode to intergranular fracture.

A timeline of key experimental findings purporting to support the decohesion mechanism as well theoretical developments are provided in the review by Gerberich. $^{[57]}$ A major advance was the development of the threshold (macroscopic) stress intensity model proposed by Gerberich and coworkers and the subsequent incorporation of the dislocation shielding concepts at crack tips, which were based on the experimental observations of $\mathrm{Ohr}^{[58,59]}$ and models of Thomson. ${ }^{[59]}$ The situation explored by Gerberich and coworkers is depicted in Figure 2, which shows dislocation emission from a crack tip with the dislocation structure being represented by a linear array of dislocations. ${ }^{[60]}$ This structure yielded for the mode I threshold stress intensity, $K_{I_{\mathrm{th}}}$ :

$$
K_{\mathrm{Ith}} \approx \frac{1}{\beta^{\prime}} \exp \left[\frac{\left(k_{\mathrm{IG}}-\alpha C_{\mathrm{H}}\right)^{2}}{\alpha^{\prime} \sigma_{\mathrm{ys}}}\right] .
$$

Here $\beta^{\prime}, \alpha^{\prime}$, and $\alpha$ are constants, $k_{\mathrm{IG}}$ is the local stress intensity factor, $C_{H}$ is the local hydrogen concentration and $\sigma_{y s}$ is the yield strength. By using this approach it was possible to obtain the high hydrogen concentrations needed at the crack tip to reduce the bond strength by significant amounts such that bond breakage was a possibility. It is worth mentioning here that in the derivation of Eq. [1], the effects of hydrogen on plasticity are ignored altogether. The expression is derived based on a super-dislocation model that is used to simulate the dislocation pile-up emerging from the crack tip. It is therefore important to validate that this depiction of the crack tip dislocation structure is representative of that generated at and ahead of a crack propagating in the presence of hydrogen.

Dewald et al. ${ }^{[61]}$ demonstrated that the concept of the dislocation-free zone and the dislocation pile-up model as described by $\mathrm{Ohr}$ et al. ${ }^{[58,62,63]}$ was susceptible to artefacts of conducting experiments in electron transparent foils especially following thinning by plastic deformation. Furthermore, it is not obvious that such a simple depiction of the dislocation structure is an appropriate representation of the evolved microstructure immediately ahead of a propagating crack. Recently, it has been shown that this microstructure is significantly more complex than that depicted in Figure 2. For example, Gross et al. examined the microstructure on a single edge notched tension specimen in Haynes 230 following 53360 fatigue cycles as a function of distance from an arrested crack tip. ${ }^{[64]}$ The undeformed microstructure, seen in the bright-field electron micrograph presented in Figure 3(a), consists of a low density of dislocations organized in arrays. This microstructure is anticipated for a material that exhibits planar slip. The microstructure beneath the sample surface at a distance of $80 \mu \mathrm{m}$ ahead of the crack tip is shown in Figure 3(b). It consists of planar slip bands, which intersect the surface to produce the steps on it. At this level of deformation, there is a strong correlation between the surface steps and the evolved microstructure. The existence of this microstructure would be predicted based on prior knowledge of deformation processes. The cross-sectional volume extracted by using focused-ion beam machining that contained the crack tip region is shown in Figure 3(c); the arrow marks the direction of crack propagation and the solid line the approximate position of the crack flanks. The evolved microstructure from the region indicated by the white box in Figure 3(c) is shown in the bright-field electron micrograph presented in Figure 3(d); the arrowheads indicate the crack surface. Clearly, the microstructure has evolved from one with an average grain area of $50 \mu \mathrm{m}^{2}$ to one containing nano-sized sub-grains at the crack flank to a banded structure that appears consistent with the geometrically necessary grain boundaries seen in cold rolled metals. ${ }^{[65,66]}$ These features are indicative of very high levels of strain. Such refinement of the microstructure along with the gradation as a function of distance from the crack flank would not be predicted based on the slip step pattern on the surface. Furthermore, this level of refinement and the complexity of the self-organization would not be captured in a simple discrete dislocation model. Of course this microstructure evolved in the absence of hydrogen and it is pertinent to ask if hydrogen could prevent this degree of refinement and self-organization. From the few studies that have been reported, it is evident that refinement also occurs in the presence of hydrogen although there are some specific details that appear dependent on the environment. ${ }^{[41]}$

Another significant advance was introduced by Gangloff and coworkers. They adopted a different approach, strain gradient plasticity theory, to increase the stressenhancement of hydrogen concentration ahead of a crack tip. ${ }^{[67]}$ However, use of the strain gradient theory should be made with caution given the number of uncertainties involved, e.g., negative crack tip stresses depending on the theory and associated length used, etc. ${ }^{[68]}$ Certainly negative stresses at the crack tip will suppress hydrogen uptake and as a consequence will not allow the needed elevation in the hydrogen concentration to be established. Nevertheless, these contributions and developments marked significant milestones and 

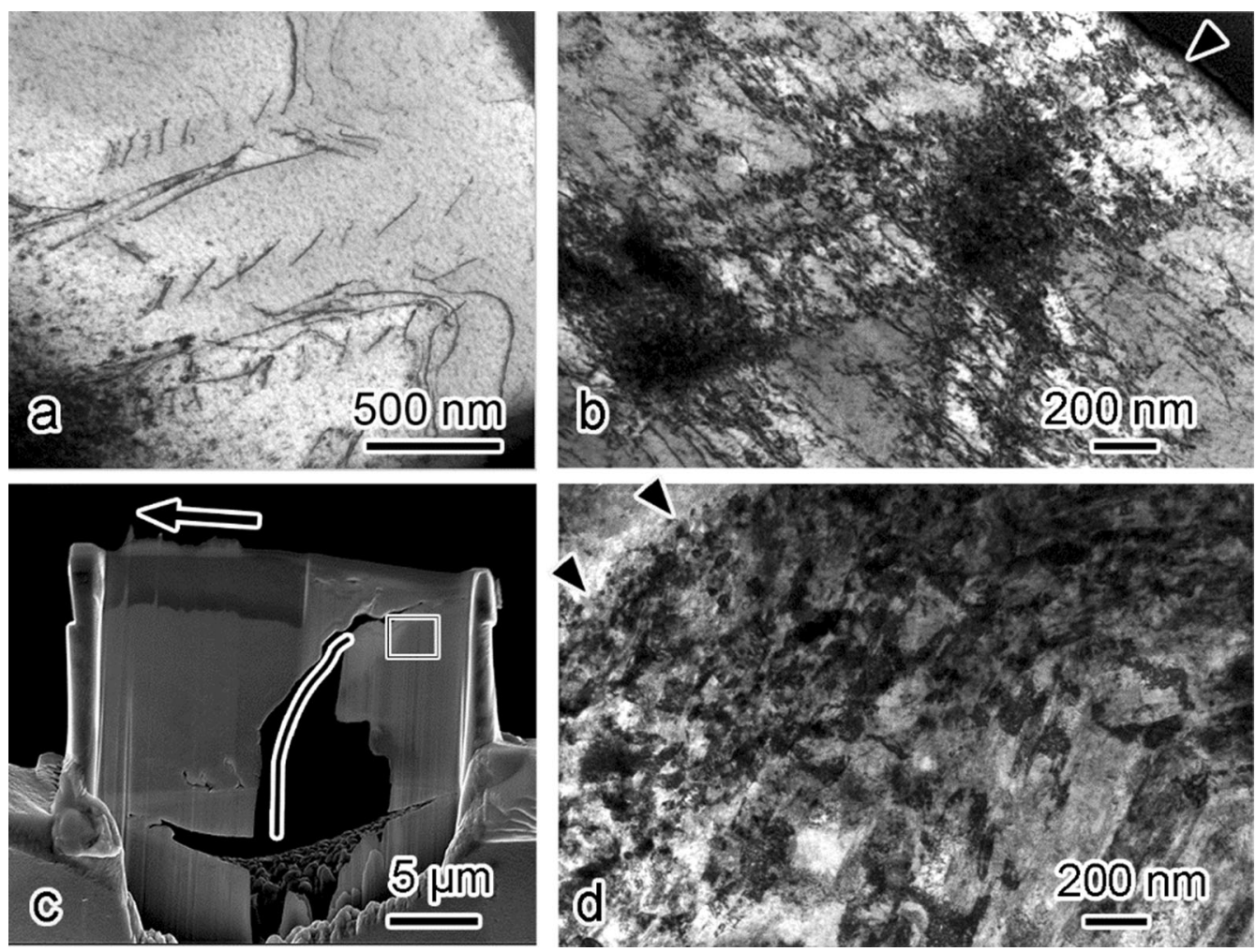

Fig. 3-Microstructure evolution in Haynes 230 after 53,360 fatigue cycles as a function of distance from the arrested crack. (a) bright-field micrograph showing the undeformed microstructure; $(b)$ bright-field micrograph showing the evolved microstructure beneath the sample surface (arrowhead) at a distance of $80 \mu \mathrm{m}$ from the crack tip; (c) sectioned viewed of the crack tip with the line indicating the approximate position of the crack face prior to thinning; $(d)$ bright-field micrograph showing the evolved microstructure of the region indicated in image c. Arrowheads indicate the crack flank. Adapted from Ref. [63]. Reproduced with permission from Elsevier.

reflect how progress in other fields have resulted in advancing our understanding of hydrogen embrittlement.

Although it is clear that hydrogen does cause a reduction of the bond strength of the lattice or the cohesive energy of the grain boundary under equilibrium conditions, there remain questions about the magnitude of the reduction as a function of hydrogen concentration and the magnitude of the decrease necessary for it to determine and dictate failure pathways. Furthermore, it is a challenge to understand how this mechanism can have any significant impact under dynamic fracture conditions such as the ones that prevail during crack propagation.

\section{HYDROGEN-ENHANCED DISLOCATION MOTION}

The first interpretation that the ductile features evident on hydrogen-induced failure surfaces were indicative of hydrogen enhancing plasticity processes was made by Beachem in 1972. ${ }^{[7]}$ This interpretation was based entirely on the a posteriori interpretation of ductile features on failed surfaces in terms of plasticity and not on direct insight to the evolved microstructure or to direct evidence for hydrogen influencing the plasticity. In the same paper Beachem suggested that the hydrogeninduced fracture surfaces were linked directly with the microstructural state. These assertions marked a significant turning point in our thinking of hydrogen embrittlement mechanisms. All previous explanations assumed the ductile features evident on fracture surface were simply aftereffects of the embrittlement process and therefore inconsequential in terms of the mechanism. ${ }^{[69-}$ ${ }^{71]}$ What makes Beachem's interpretations remarkable, is that is now apparent that the morphological features evident on fracture surfaces do not give an accurate depiction of the underlying deformation process that determined the failure mode or path.

Direct experimental evidence for hydrogen enhancing the mobility of dislocations was provided by the "Illinois group" led by Birnbaum, Robertson, and Sofronis. They conducted deformation experiments inside a transmission electron microscope (TEM) that had been modified to allow the sample volume within the objective pole-piece to be flooded with a gaseous hydrogen environment. ${ }^{[72]}$ Gas pressures up to $20 \mathrm{kPa}$ could be introduced, although dissociation and ionization of the $\mathrm{H}_{2}$ molecule by the electron beam increased the fugacity by several orders of magnitude. ${ }^{[73]}$ Two types of experiment were conducted. The first involved introducing the gas environment while the rate of displacement of the stage was constant. The effect was seen in the change in the velocity of the dislocations. The second experiment involved generating mobile dislocations, holding the applied displacement of the stage constant and allowing the dislocation motion to stop, 
adding the hydrogen gas to the microscope, and observing the effect on the stationary dislocations. The results from both experiments were consistent and showed that the introduction of hydrogen gas caused the dislocation velocity to increase. Removing the gas from the microscope reversed the effect and the dislocations stopped moving. The effect was found to be independent of the material structure and dislocation type but dependent on the material purity and on the pressure of hydrogen gas that was introduced. ${ }^{[8,30,31]}$

An example of this effect is shown in the series of time-resolved images presented in Figure 4. ${ }^{[8]}$ In this example, the dislocations were generated by deforming a Fe sample in vacuum, then the applied load was held constant and hydrogen gas was introduced after the dislocations had come to rest. Adding the hydrogen gas caused the dislocation motion to increase. The induced motion can be seen by comparing the images presented in Figure 4. An indication of the dislocation velocity can be surmised from the times of each frame shown; the video of this interaction is provided as supplemental material video 1 . To better illustrate this enhanced motion, difference images generated by superimposing a negative image of the dislocation configuration at a later time on a positive image showing the configuration at an earlier time are presented in Figure 5; the arrow indicates the direction of motion. These difference images are interpreted as follows: dark features show the earlier positions, white features show positions at the later time and lack of contrast shows no change between the two states. Clearly, motion of the dislocations has been induced by the presence of hydrogen.
The presence of hydrogen was found to enhance the rate at which dislocation sources operated. An example of this effect in $\mathrm{Fe}$ is shown in the time series of images presented in Figure 6; the video from which this sequence was generated is provided as supplemental material video 2. ${ }^{[74]}$ The arrowheads in Figure 6(a) show three sources that are activated by the introduction of hydrogen gas to the system. The arrows in each image indicate the direction of motion of the dislocations. Source 3 has completed a revolution by Figure 6(h) and is expanding again in Figure 6(i). Dislocation 1 is seen expanding and breaking into two segments that move in different directions as it intersects the free surface. The change in the configuration of the dislocations is evident if Figures 6(a) and (o) are compared.

The observations of hydrogen-enhanced dislocation motion were challenged initially, and it was suggested that this was a thin foil effect or attributable to the pressure difference created by the introduction of the gas environment into the objective pole-piece of the electron microscope. To demonstrate that dislocation motion was achieved only in the presence of hydrogen, the experiments were repeated using either dry or water saturated inert gases. ${ }^{[75,76]}$ Enhancement of the dislocation motion occurred only in the water saturated state, which was attributed to the hydrogen generated from the water. With the electron transparent foils, the time to equilibrate with the surrounding gas pressure was a matter of seconds and it was shown that the effect could continue at constant hydrogen pressures for times significantly greater than the few seconds it took the system to equilibrate. Finally, macroscale experiments
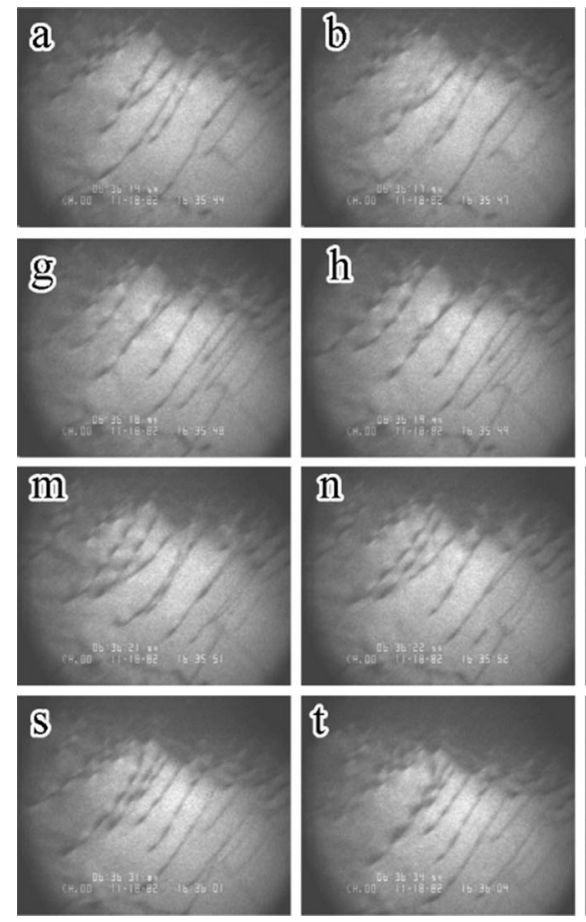
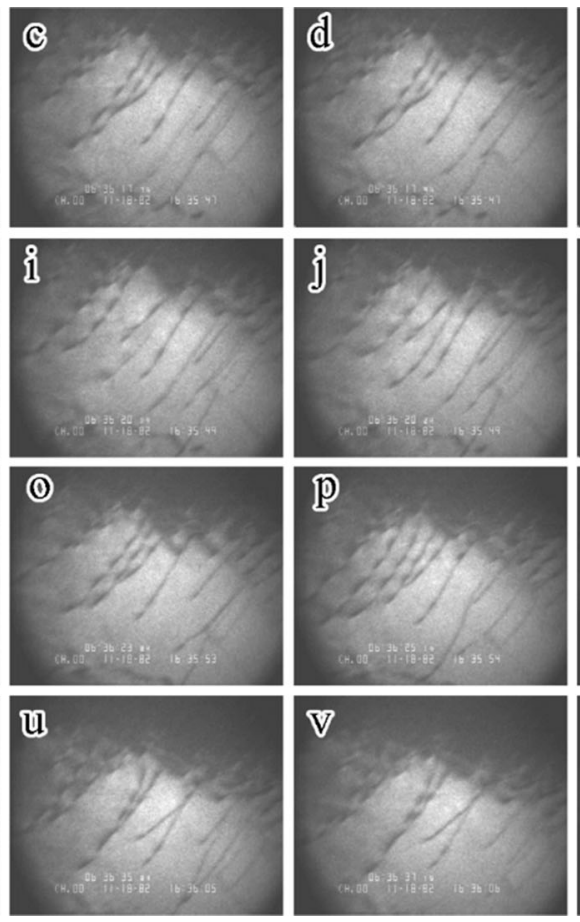
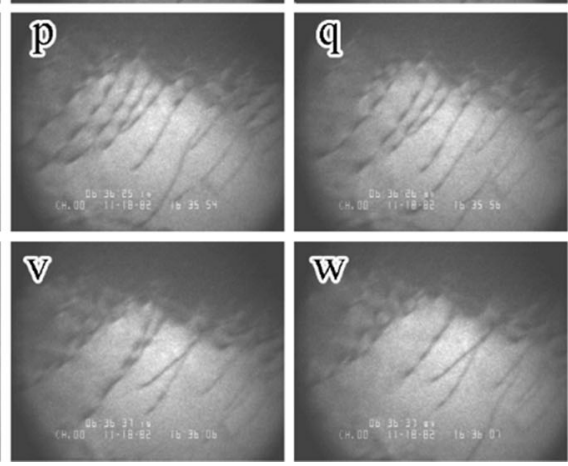
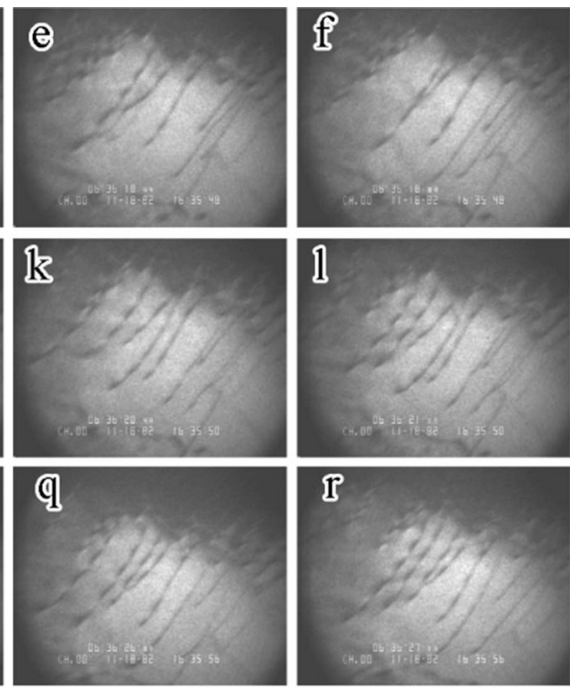

Fig. 4-Time-resolved series of images showing the motion of dislocations caused by hydrogen. The time of each image is given units of seconds and 100th of a second. (a) 14:64; (b) 17:54; (c) 17:74; (d) 17:94; (e) 18:44; (f) 18:82; (g) 18:91; (h) 19:44; (i) 20:04; (j) 20:24; (k) 20:48; (l) 21:14; (m) 21:77; (n) 22:35; (o) 23:84; (p) 25:14; (q) 26:46; (r) 27:17; (s) 31:87; (t) 34:57; (u) 35:77; (v) 37:14; (w) 37:87. See video 1 in supplemental material. Adapted from Ref. [8]. Reproduced with permission from Elsevier. 

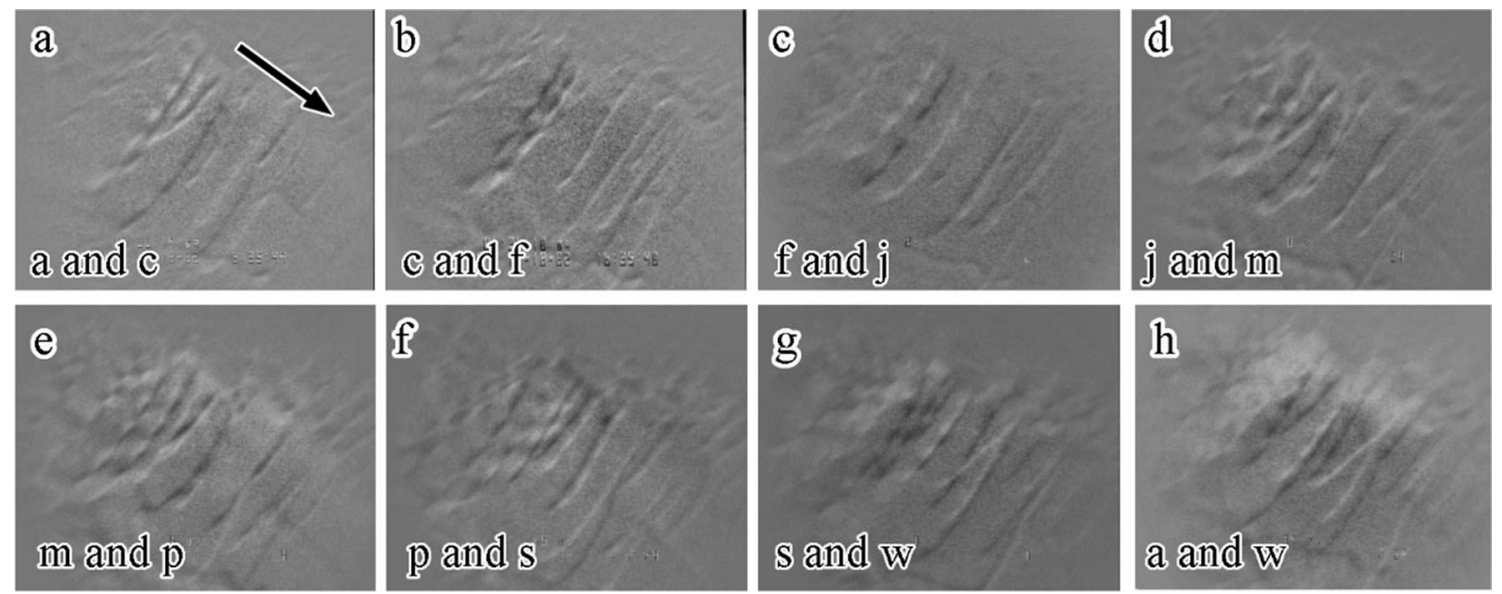

Fig. 5-Difference images constructed from the images presented in Fig. 4. The images combined are listed in the lower left, with the latter being a negative which was added to a positive of the former. White and black images show new and old positions, respectively.
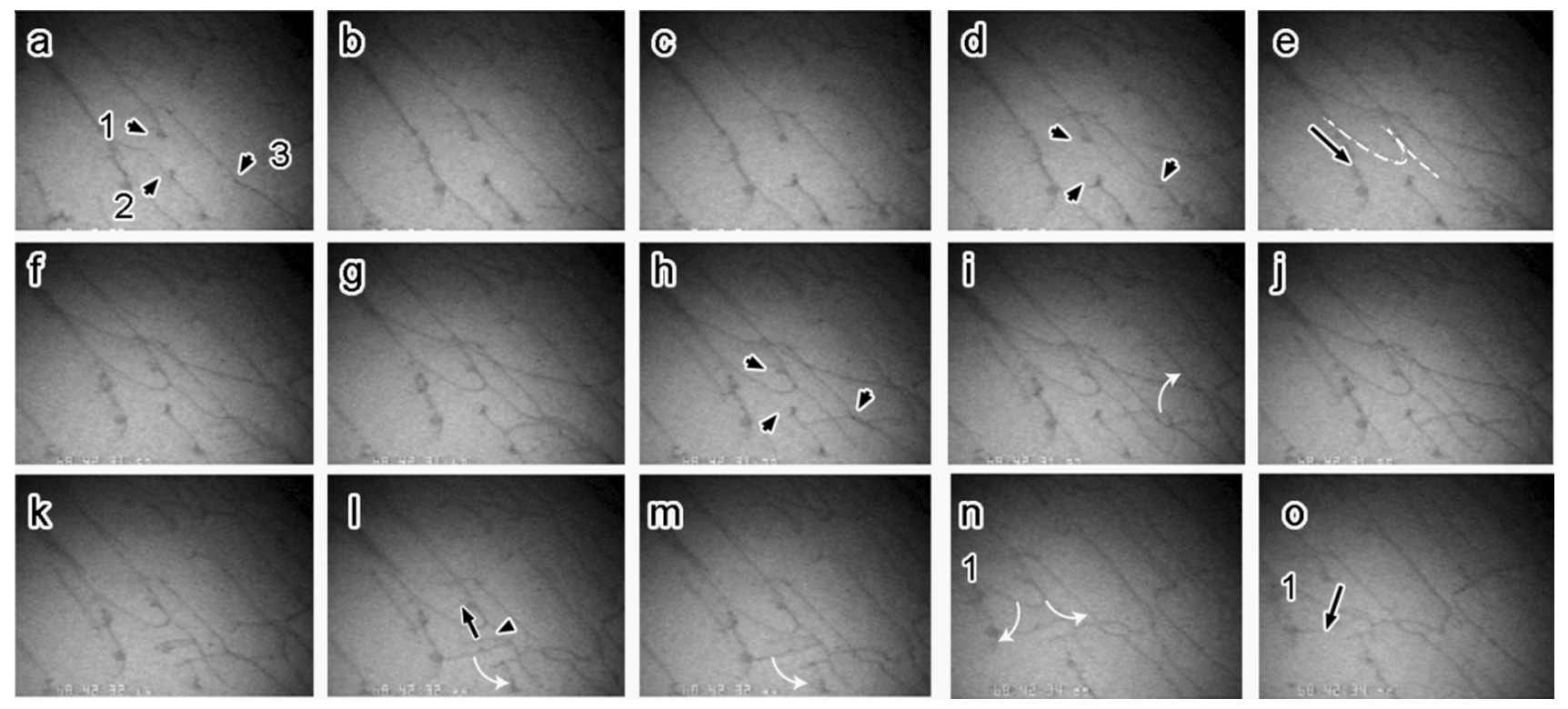

Fig. 6- Operation of dislocations sources in Fe due to the introduction of hydrogen gas. Arrowheads mark the sources, arrows mark the direction of motion of the dislocations. See video 2 in supplemental material.

such as stress relaxation or strain rate change tests have been conducted on a number of metals with the analysis consistently showing that the presence of hydrogen decreased the activation area for dislocation motion and the activation energy. ${ }^{[77-79]}$ Such reductions are interpreted as hydrogen enhancing the mobility of dislocations.

Other experiments that were conducted during the in situ TEM straining experiments involved observing what happens to a stationary but stressed crack as hydrogen gas or water-saturated inert gas was introduced into the electron microscope. These experiments were conducted in regions that were initially opaque to the electron beam; that is they were several hundred nanometers thick before deformation. The result was extensive thinning of the material ahead of the crack by dislocation processes followed by rapid crack propaga- tion. On removal of the hydrogen gas from the microscope, the crack propagation stopped. It could be restarted by reintroducing the hydrogen gas. An example of hydrogen-induced crack propagation in $\mathrm{Fe}$, albeit still in a thin foil, is demonstrated in the series of time-resolved images presented in Figure $7 .{ }^{[8,74,80]}$ Crack advance is preceded by extensive thinning ahead of the crack; this is illustrated by the sets of parallel lines. The crack is also seen to widen. Propagation of the crack is rapid, as can be assessed by comparing Figures $7(\mathrm{~m})$ through (q), which span a total time of $70 / 100$ th seconds. Also apparent from the images is that the crack propagation direction changes, indicated by the arrows, as the crack advances.

The hydrogen-induced transition in the failure mode from transgranular to intergranular was also observed in the electron transparent foils used in the in situ TEM 

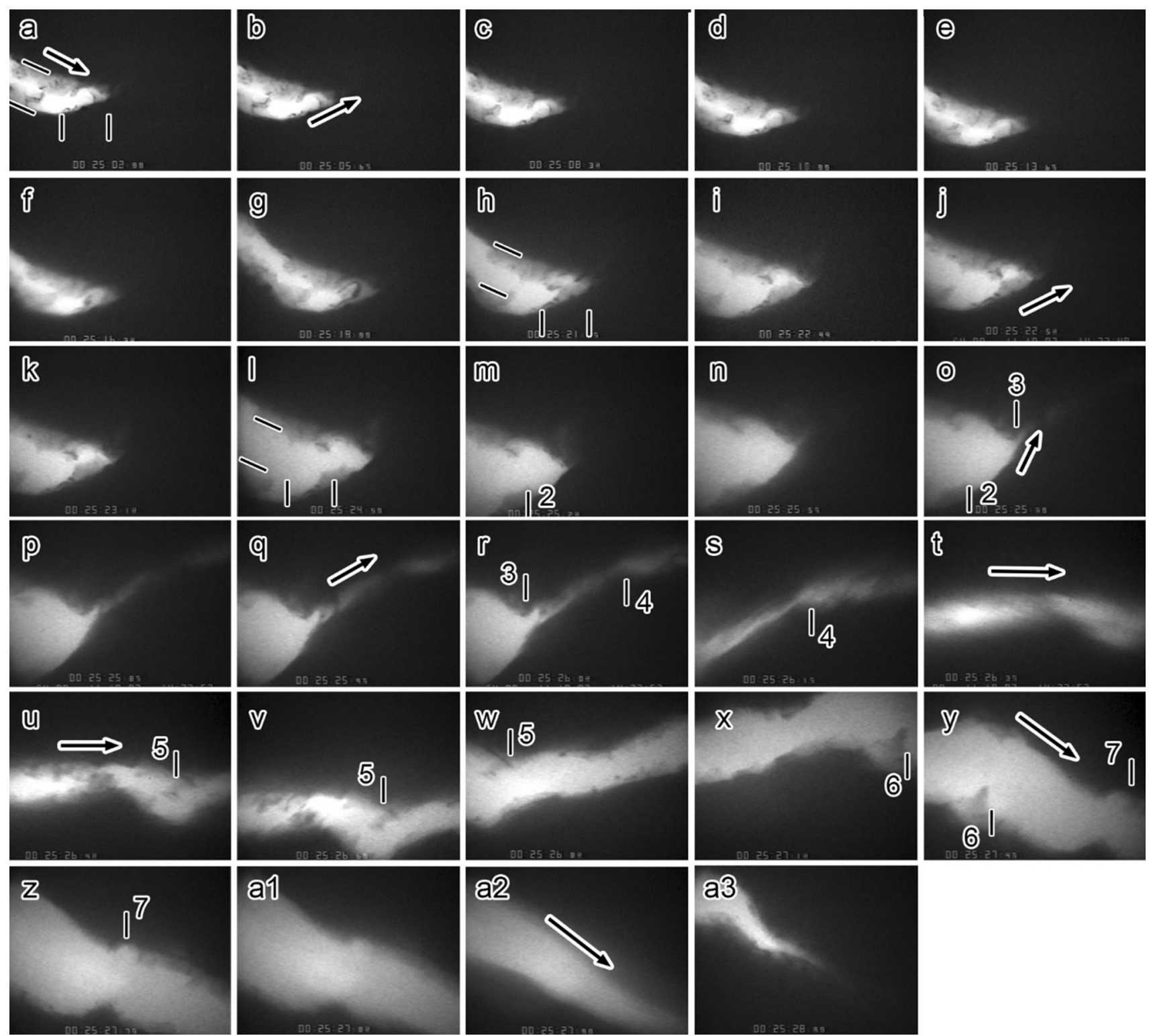

Fig. 7-Hydrogen-induced cracking in Fe. The times of the images are given as seconds (and 1/100th of a second) (a) 02; (b) 05; (c) 08; (d) 10; (e) 13; (f) 16; (g) 19; (h) 21; (i) 22 (44); (j) $22(54) ;(k) 23 ;(l) 24 ;(m) 25(29) ;(n) 25(59) ;(o) 25(69) ;(p) 25(89) ;(q) 25$ (99); (r) 26 (04); (s) 26 (19); (t) 26 (39); (u) 26 (43); (v) 26 (68); (w) 26; (x) 27 (18); (y) 27 (49); (z) 27 (79); (a1) 27 (89); (a2) 27 (98); and (a3) 28. See video 3 in supplemental material. Adapted from Ref. [8]. Reproduced with permission from Elsevier.

deformation experiments. ${ }^{[81,82]}$ For example, the failure mode in $\mathrm{Ni}$ that had been heat treated to segregate $\mathrm{S}$ to the grain boundaries was transgranular in the absence of hydrogen and intergranular in the presence of hydrogen. ${ }^{[81]}$ Similarly, $\mathrm{Ni}_{3} \mathrm{Al}$ with boron exhibited transgranular failure in the absence of hydrogen and mixed transgranular/intergranular failure in the presence of hydrogen. ${ }^{[82]}$ These results were consistent with those from bulk studies. ${ }^{[83,84]}$

Based on the consistency of the results across multiple systems on the effects of hydrogen on dislocation generation and mobility, as well as crack advance, ${ }^{[8]}$ the reversibility of the hydrogen effect including the reversible change in the equilibrium separation distance in a dislocation pile-up; ${ }^{[85]}$ the ability to transition the failure mode; ${ }^{[81,82]}$ and the similitude between the results of the in situ TEM studies and macroscale experiments designed to probe the influence of hydrogen on the properties of dislocations, one can conclude that the in situ TEM deformation experiments have provided insight as to the influence of hydrogen on the behavior of dislocations. In its purest and simplest form, hydrogen enhances the production and mobility of dislocations irrespective of dislocation type and crystal structure.

The explanation for hydrogen enhancing the mobility of dislocations was proposed by Birnbaum and Sofronis in terms of a hydrogen shielding concept; this became the basis for the hydrogen-enhanced localized plasticity (HELP) mechanism of hydrogen embrittlement. ${ }^{[9,86]}$ Effectively the shielding concept considers the influence of having hydrogen segregated to the stress fields of dislocations, as well as to other elastic obstacles. The 
accommodation of hydrogen modifies the stress field of the defect to which it is attached. In the case of dislocations, this will modify the stress field such that it is increased in some directions and decreased in others. Consequently, in those directions in which it is reduced, the interaction energy of the dislocation with obstacles that impede its motion will be reduced. ${ }^{[9,87]}$ In other words, the attachment of hydrogen to the dislocation allows it to move at a lower stress level in certain directions. It should be mentioned here that recently Pezold et al. used a hierarchical approach that combined ab initio electronic structure calculations, semi-empirical embedded atom method potentials and a lattice-gas Hamiltonian to probe the HELP mechanism in the $\mathrm{NiH}$ system. ${ }^{[88]}$ They concluded that $\mathrm{H}-\mathrm{H}$ interactions play an important role in reducing the level of hydrogen concentration required for shielding brought about by the formation of local hydride-like regions, thus creating favorable conditions for the HELP mechanism to operate even at low concentrations. In addition to supporting the enhanced mobility of dislocations, the hydrogen shielding model predicts that dislocationdislocation interactions will be influenced by hydrogen. One manifestation of the hydrogen-modified dislocation-dislocation interaction is that the equilibrium separation distance between dislocations in an array such as a dislocation pile-up is decreased in the presence of hydrogen. This effect has been observed experimentally ${ }^{[85]}$ and is supported by theoretical calculations. ${ }^{[89]}$

Of course, for the hydrogen-enhanced dislocation motion to be more than a transitory effect, the hydrogen environment must travel with the dislocation. This requirement incorporates a natural dependence on the strain rate, stress and temperature. At high strain rates and high stresses, the dislocation velocity will exceed that at which the dislocation will break-away from the hydrogen environment. At elevated temperatures, the hydrogen will not remain bound to the dislocation. Indeed, outside the strain rate or temperature windows, the presence of hydrogen in the lattice will act as a conventional solid solution strengthening agent and impede the motion of the dislocations. Dragging the hydrogen atmosphere with the dislocations provides a natural explanation for limiting cross-slip and increasing slip planarity as the hydrogen atmosphere would have to be redistributed to enable the constriction to occur or for the dislocation to reorient to the necessary screw configuration. There is no additional driving force to make this happen and, consequently, the dislocations are constrained to continue to glide on the primary slip plane. This locking of the dislocations to a specific slip plan, which prohibits cross-slip, has been observed experimentally. ${ }^{[85]}$

\section{CORRELATING THE EVOLVED MI- CROSTRUCTURE WITH THE FRACTURE MECHANISM AND PATHWAY}

Based on the above experimental results and the resultant modeling efforts, the assertion that hydrogen influences the plasticity appears irrefutable. The remaining challenge has been to link this enhanced mobility to the macroscale result of hydrogen-induced and enhanced failure. Until recently this connection has been driven by continuum modeling. ${ }^{[90-92]}$ However, with the development of new tools, specifically the focused-ion beam instrument, it is now feasible to observe the microstructure immediately beneath the fracture surface and to probe the connection. ${ }^{[10]}$ In the following, the microstructure that has evolved beneath the different key features found on hydrogen-induced fracture surfaces is described, covering voids, "quasi-cleavage" and flat surfaces, as well as intergranular facets. Where possible, a comparison is made between the evolved microstructure beneath fracture surfaces in uncharged and hydrogen-charged materials.

The first example considers the microstructure beneath voids. To enable a comparison of the microstructure in uncharged and hydrogen-charged material, both states were studied in a middle carbon high-strength martensitic steel $(0.2$ pct proof stress of $1090 \mathrm{MPa})$ containing a high density of nano-sized (Ti,Mo)C precipitates. $^{[13]}$ This material contained 0.82 mass ppm (45.9 at.ppm) hydrogen. This hydrogen concentration resulted in a decrease in the maximum nominal bending stress for fracture in a 4-point bend specimen from $2128 \mathrm{MPa}$ to $1260 \mathrm{MPa}$. The fracture surface of the uncharged material consisted of microvoids whereas the hydrogen-charged material showed microvoids and "quasi-cleavage" features; compare the SEM images of the fracture surfaces that are presented in Figures 8(a) and (c), respectively. The microstructure beneath the voids produced in the absence and presence of hydrogen is shown in the bright-field electron micrographs presented in Figures 8(b) and (d), respectively. In both micrographs, the void surface is marked by the white line. From these examples, it is evident that the level of strain beneath the void surface is substantial in the presence and absence of hydrogen. Both microstructures exhibit a banded structure that is similar in appearance to the geometrically necessary boundary and incidental dislocation boundaries generated in highly strained material; ${ }^{[65]}$ the magnitude of the rotation between the bands needs to be measured to ascertain the nature of the bands. There are no obvious differences in the microstructure beneath the voids produced in the uncharged and hydrogen-charged materials although it is possible that there may be differences in the dimensions of the banded structure, the depth beneath the fracture surface to which the banded structure extends or the magnitude of the misorientations between the bands. These differences are being explored currently.

A commonly used description of regions of hydrogeninduced fracture surfaces is "quasi-cleavage" i.e., failure on non-cleavage planes with fine lines that run approximately parallel to the direction of crack advance. For example, regions of "quasi-cleavage" failure are seen on the fracture surface of the hydrogen-charged high-strength martensitic steel containing a high density of nano-sized (Ti,Mo)C precipitates, ${ }^{[13]}$ an ultra-high strength martensitic steel, ${ }^{[14]}$ and an API grade X60 pipeline steels tested under high hydrogen gas pressures. ${ }^{[12]}$

Nagao et al. compared the evolved microstructure beneath the "quasi-cleavage" surface produced in the 

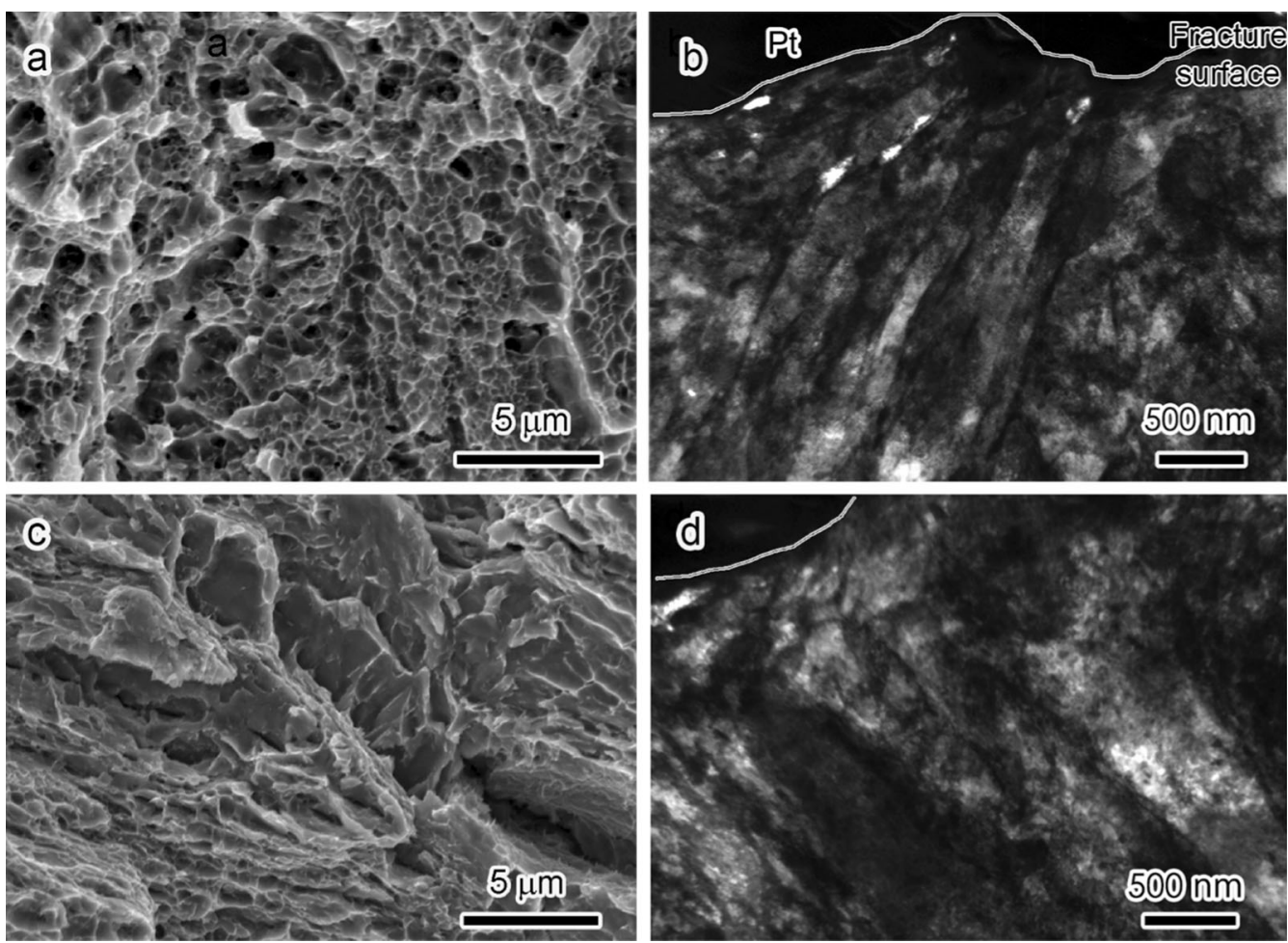

Fig. 8- Comparison of the microstructure beneath voids produced in a middle carbon high-strength martensitic steel containing a high density of nano-sized (Ti,Mo)C precipitates. (a) SEM image of the fracture surface in the absence of hydrogen; $(b)$ bright-field electron micrograph showing the microstructure generated beneath a void in the absence of hydrogen; $(c)$ SEM image of the fracture surface in the presence of 0.82 mass ppm (45.9 at.ppm) of hydrogen and $(d)$ bright-field electron micrograph showing the microstructure generated beneath a void in the presence of hydrogen. The white lines trace the approximate location of the void surface. Adapted from Ref. [13]. Reproduced with permission from Elsevier.

hydrogen-charged lath martensitic steel tested at room temperature with the underlying microstructure beneath a "quasi-cleavage" surface generated in the uncharged lath martensitic steel tested at low temperature. ${ }^{[14]}$ In the hydrogen-charged material, the "quasi-cleavage" surface was along the lath boundary and involved high levels of deformation that disrupted the lath boundaries. In contrast beneath the surface produced in the low temperature test, the microstructure was similar to the undeformed material and the crack propagated through the lath martensite. Therefore, despite the fracture surfaces exhibiting similar morphologies, the associated deformation was dissimilar. Nagao et al. found that the presence of the nano-sized (Ti,Mo)C in the lath martensite steel did not alter the "quasi-cleavage" pathway or mechanism in the presence of hydrogen, it was still driven by intense plastic deformation and propagated along the lath boundary. ${ }^{[13]}$

The fracture surfaces of the compact tension tests of API X60 grade pipeline steel tested under high-pressure hydrogen gas exhibited regions that would be classified as "quasi-cleavage" as well as ones that appeared flat. ${ }^{[11,12]}$ The morphology of the "quasi-cleavage" surface is shown in Figure 9. ${ }^{[12]}$ Figure 9(a) shows a low resolution SEM image of such a surface with the classic river markings. At higher resolution, the river markings are seen to be capped with saw-teeth, Figure 9(b), that are electron transparent even in the SEM image. The underlying microstructure beneath these features is shown in the bright-field electron micrograph presented in Figure 9(c). This sample was produced using focused-ion beam machining with the sample extracted perpendicular to the river markings. The river markings are evident in the electron micrograph. Beneath the surface the dislocations form deformation bands that run parallel to the ridge edges; examples are indicated with arrows in Figure 9(c). Martin et al. proposed that this surface was generated by a void process with the voids nucleating at the intersections of the deformation bands. ${ }^{[12]}$ The saw-teeth were attributed to the final failure process that occurs in thin material and deemed irrelevant to the hydrogen embrittlement process.

An example of a flat surface in the hydrogenembrittled API X60 grade steel is shown at different spatial resolutions in Figure $10 .^{[11]}$ Clearly, what appears to be a flat surface when viewed at low spatial resolution, Figure 10(a), is not when viewed at higher resolution using either the SEM, Figure 10(b), or atomic force microscope, Figure 10(c). The appropriate nomenclature to describe this surface is unclear. Is it dimpled, are the dimples related to nano-void coalescence, are these remnants of the final separation process similar to the saw teeth on top of the "quasi-cleavage" ridges seen in Figure 9(b)? Regardless of the terminology used to describe this surface, the underlying microstructure again consists of a dislocation structure that extends well beneath the fracture surface. Martin et al. attribut- 

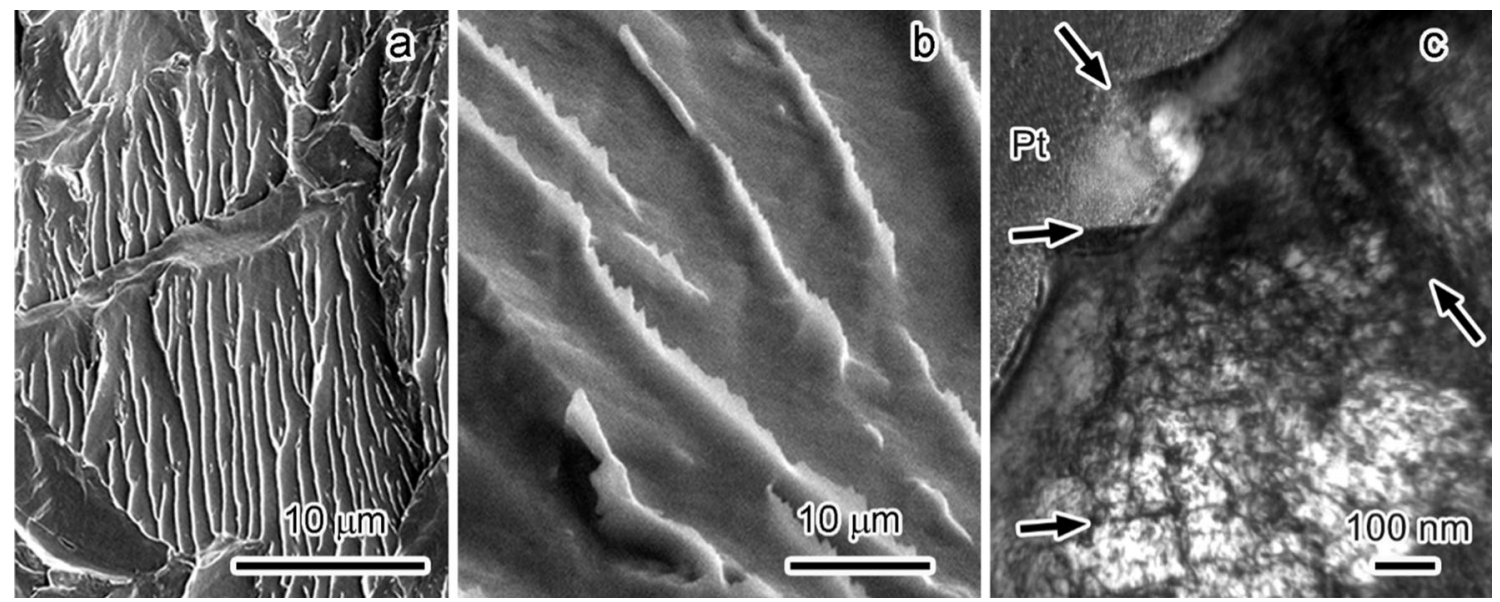

Fig. 9-Hydrogen-induced "quasi-cleavage" surface of API X60 grade steel. (a) low-resolution SEM image of the fracture surface showing the surface markings; $(b)$ high resolution SEM image of the river markings capped with "saw-teeth;" and $(c)$ bright-field electron micrograph of the underlying microstructure with the surface and ridges intact. Adapted from Ref. [12]. Reproduced with permission from Elsevier.
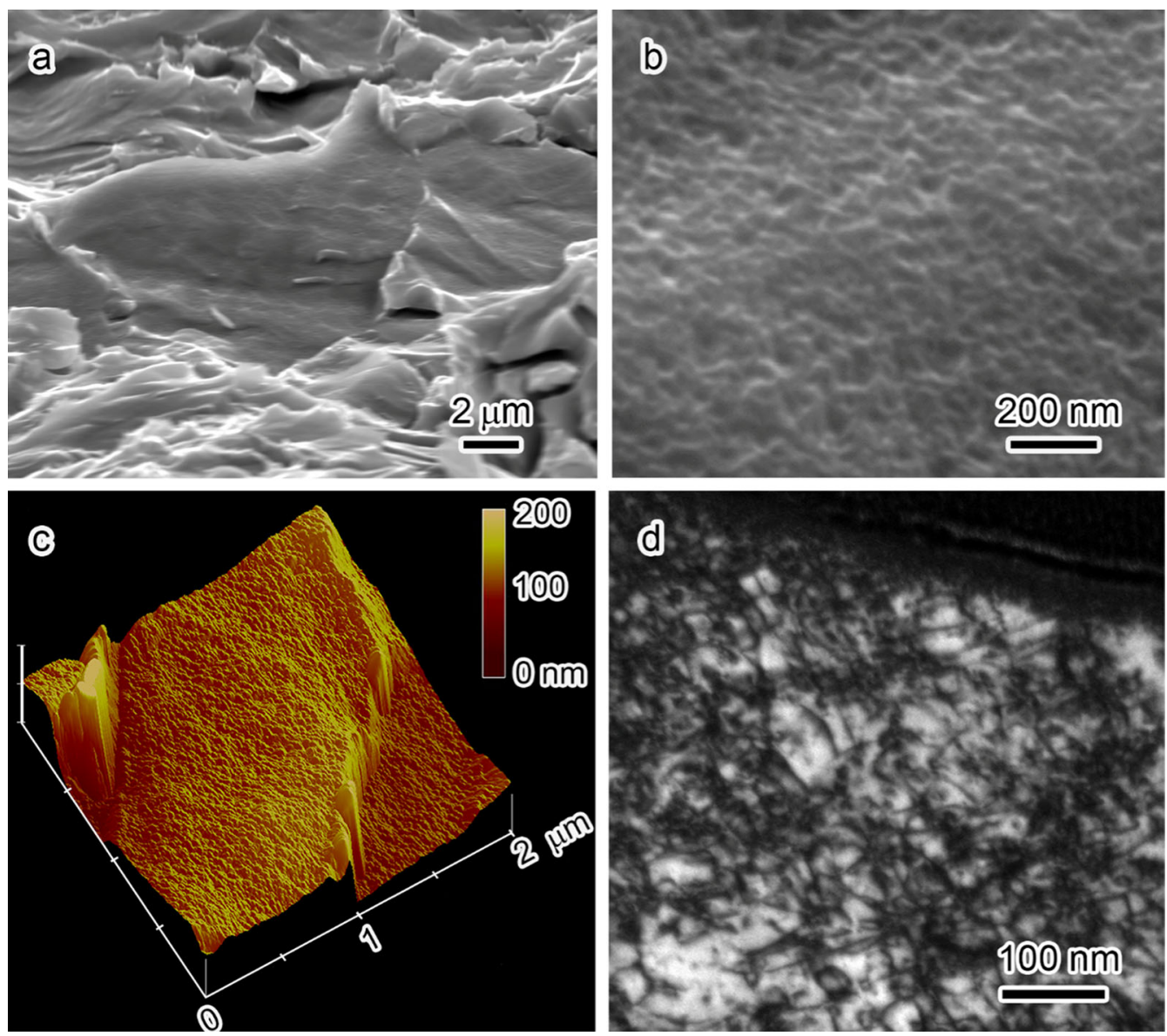

Fig. 10-Hydrogen-induced flat fracture surface of API X60 grade steel: (a) low resolution SEM image; $(b)$ high resolution SEM image showing a dimpled surface; $(c)$ atomic force microscope image of a dimpled surface and $(d)$ underlying microstructure. Adapted from Ref. [11]. Reproduced with permission from Elsevier.

ed the difference in fracture surfaces and the underlying microstructures between flat and "quasi-cleavage" to differences in deformation processes that reflect the orientation of the grains and the resulting stress state from the applied stress and local constraints imposed by surrounding grains. Interestingly, in the electron micrographs presented by Martin et al., the deformation and the fracture path ignored a series of carbides, both located on the grain boundary and within the grain interior. ${ }^{[11]}$ This result suggests that, contrary to a well- 
held belief, ${ }^{[93]}$ carbides are not necessary for initiation of hydrogen-induced fractures. Further work is required to discern the role of carbides and plasticity in hydrogeninduced failures.

Others have offered a very different explanation of the flat dimpled surface. ${ }^{[94,95]}$ Srinivasan and Neeraj suggested that the surface morphology and the fracture path and mechanism are governed by the self-assembly of vacancies that are stabilized by hydrogen and the density of which is promoted by the presence of hydrogen and the deformation processes. While the production of vacancies or small vacancy clusters can occur during deformation, and the presence of hydrogen can decrease the formation energy of defects, it is necessary to consider how the agglomeration of the vacancies occurs to generate the fracture surface, why defects with similar dimensions to the surface features are not found elsewhere beneath the surface and how the vacancy agglomeration mechanism explains the "quasicleavage" regions that exist on the same fracture surface. Assuming the surface features are representative of the failure mechanism, it is pertinent to consider if vacancy clusters along the fracture plane serve as the nucleation sites for the formation of the surface void features. If the nucleation sites are the vacancy clusters, they should persist throughout the lattice which would mean they should influence the deformation processes prior to failure. Having such a dense field of obstacles would influence the mobility of dislocations much in the same way that vacancy clusters produced by irradiation influence the behavior-here they result in a strengthening of the matrix and the deformation is restricted to channels in which the defect density is reduced by the passage of dislocations. ${ }^{[96-100]}$ Lastly, there is no experimental evidence, to our knowledge, that demonstrates how a nano-sized vacancy-produced "void" can grow to become micron-sized and coalescence with another void to produce fracture. Stresses needed to grow nano-sized voids are in the GPa range, whereas in mild steels embrittlement can occur in the MPa range. An alternative explanation for the formation of these features on the flat surface is that they are generated in a manner similar to the saw-teeth observed atop the ridges, river markings, on the "quasi-cleavage" surface, Figure 9(b). These were attributed to the very final stages of separation and even if they were influenced by hydrogen, they are inconsequential in establishing the conditions that promote failure initiation.

In some systems, the presence of hydrogen is known to cause a transition in the failure mechanism from transgranular to intergranular. ${ }^{[15,16,84,93,101-104]}$ An example of a hydrogen-induced intergranular fracture surface of Ni 201 containing 2000 at. ppm of hydrogen is shown in Figure 11. ${ }^{[15]}$ The SEM image, Figure 11(a), shows the fracture surface as 100 pct intergranular. The facets appear flat and featureless at low spatial resolution but steps are evident at higher spatial resolution as shown in the SEM and atomic force microscope images presented in Figures 11(b) and (c), respectively. It was common for more than one step direction to exist on the facet surface. A comparison of Figures 11(b) and (c) show examples of facets with three (arrows) and one step direction, respectively. Despite the obvious evidence for plasticity and the non-zero plasticity strain at which this type of intergranular failure occurs, the most common explanation for hydrogen-induced intergranular failure remains that the hydrogen-induced reduction in the cohesive strength of the grain boundary is of sufficient magnitude to cause the transition in fracture mode. This assumes that any prior plasticity that has occurred is unaffected by internal hydrogen and that this plasticity has no impact on the failure processes. In the case of the hydrogen source being external, it assumes that any prior deformation is irrelevant to the failure process.

In the Ni 201, which exhibited a strain-to-failure of 13 pct, the microstructure was determined as a function of distance from the facet surface. In Figure 12, the microstructure immediately beneath a faceted surface is compared with that at a distance of $3 \mathrm{~mm}$ from it and with the evolved microstructure obtained at strains of 10 pet in air ${ }^{[105]}$ and after 35 pet cold rolling to an effective strain of 40 pct. ${ }^{[6]}$ Immediately beneath the facet surface the microstructure shows a regular cell structure with the cell size being $200-400 \mathrm{~nm}$ in diameter, dense cell walls and dislocations within the cells. An example of this microstructure is presented in Figure 12(a). Interestingly, this microstructure existed beneath a facet that exhibited steps in one direction only. The arrowheads in this image mark steps on the
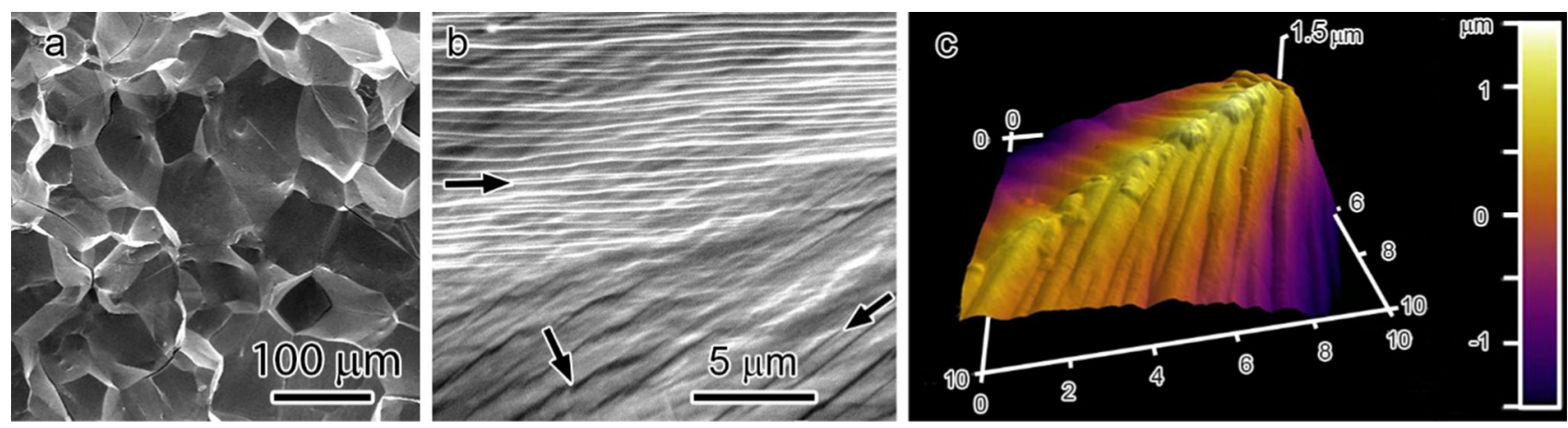

Fig. 11-Hydrogen-induced intergranular failure of Ni 201 containing 2000 at.ppm of hydrogen: (a) low resolution SEM image of the fracture surface; $(b)$ high-resolution SEM image of the fracture surface showing surface traces; and $(c)$ atomic force microscope image of an intergranular facet. Adapted from Ref. [15]. Reproduced with permission from Elsevier. 

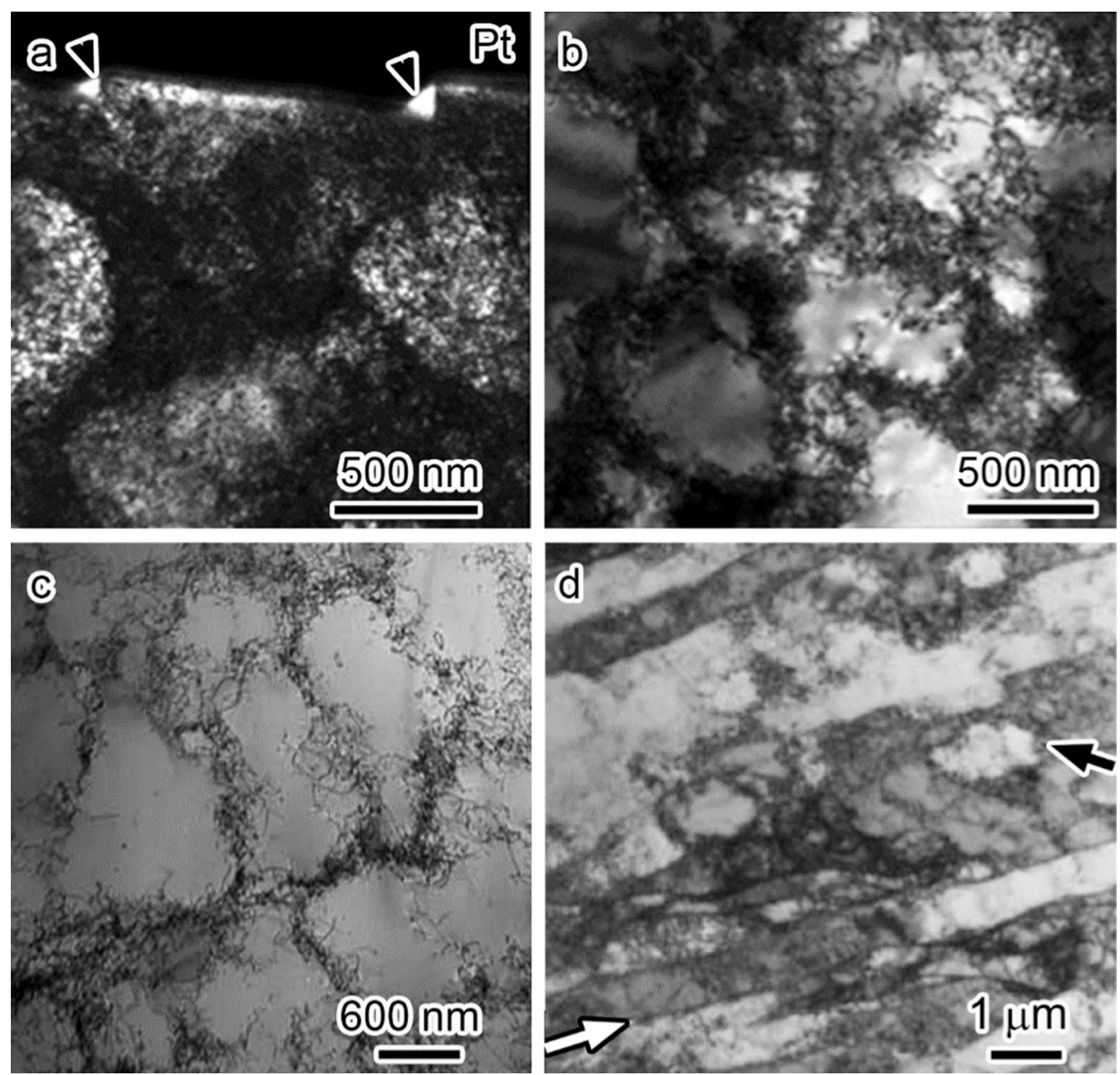

Fig. 12-Bright-field electron micrographs showing the microstructure following $(a)$ immediately below an intergranular facet in material containing hydrogen; $(b) 3 \mathrm{~mm}$ below a facet; $(c) 10$ pct strain in air; and $(d) 35$ pct cold rolled. a, b, c are adapted from Refs. [15], [105], and [66], respectively. Reproduced with permission from Elsevier.

facet surface. A refined cell structure still exists at a distance of $3 \mathrm{~mm}$ from the facet surface, Figure 12(b). Although the degree of refinement decreases with distance from the facet surface, it is still greater than expected for a sample deformed to a similar strain in an inert environment. For example, as shown in Figure 12(c), the microstructure generated in nickel deformed to 10 pct in air consists of irregular-shaped cells with dimensions of between 600 and $1200 \mathrm{~nm}$ and with cell walls in which individual dislocations can still be discerned. ${ }^{[105]}$

For the sake of discussion, if it is assumed that the cell size scales linearly with strain, cells with a diameter of $200 \mathrm{~nm}$ would not be achieved until a strain of $40 \mathrm{pct}$ in the absence of hydrogen. However, at this level of plastic strain the microstructure would have been further evolved into geometrically necessary grain boundaries (an example is indicated with a white arrow) and incidental dislocation boundaries (an example is marked with a black arrow) as shown in Figure 12(d), which is from a sample that had been cold rolled to 35 pct. ${ }^{[66]}$ Clearly, the evolved microstructure is different from that generated in the presence of hydrogen. The comparison made in Figure 12 suggests that hydrogen not only accelerates the evolution of the deformation microstructure, it also traps it in configurations that are unlikely to form in its absence.

Of course, it is necessary to show that the observation in $\mathrm{Ni}$ is not an isolated case and that an acceleration of the evolved structure occurs in other systems that have failed intergranularly. Wang et al. have examined the microstructure beneath intergranular facets in Fe containing a high hydrogen concentration. ${ }^{[16]}$ Failure occurred at a strain of 5 pct. In this case hydrogen was introduced during the test using an aggressive cathodic charging condition. However, the duration of the experiment was short so that the damage associated with the hydrogen charging condition was negligible. Examples of the intergranular fracture surface and the underlying microstructure are shown in Figure 13. ${ }^{[16]}$ No steps are evident on the fracture surface, Figure 13(a), and this is presumably from exposure to the electrolyte following failure. The underlying microstructure is shown in Figure 13(b) and it again shows a high density of dislocations that are beginning to selforganize into a cell structure. In comparison, the 

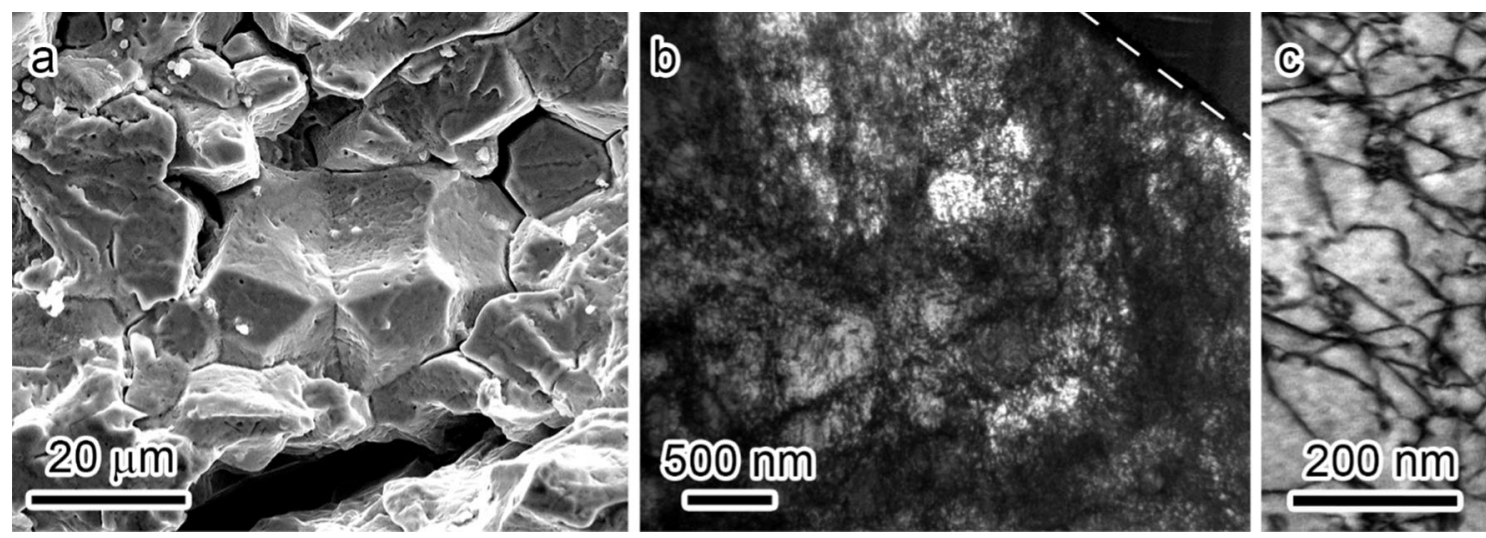

Fig. 13-Hydrogen-induced intergranular fracture of Fe following cathodic hydrogen charging during deformation: (a) low-resolution SEM image of the fracture surface; $(b)$ bright-field electron micrograph of the dislocations structure immediately beneath the facet and $(c)$ bright-field electron micrograph of the deformation structure produced at a plastic strain of 5 pct in the absence of hydrogen. Adapted from Ref. [16]. Reproduced with permission from Elsevier.

microstructure in Fe without hydrogen at a strain of 5 pct consists of a low density of dislocations that are not organized into any form of structure; compare the bright-field micrographs presented in Figure 13(b) and (c).

These two examples of hydrogen-induced intergranular fracture show the formation of a dislocation structure that is significantly greater than would be obtained in the absence of hydrogen. Furthermore, at least in the Ni case, the microstructure appears to have been stabilized in a configuration that would not persist in the absence of hydrogen. A noteworthy and distinctive point of the results presented in Figures 11 through 13 is that the microstructure beneath the facets extends over a significant volume of material and is generated under stress prior to failure rather than being attributable to the fracture event itself. In fact, it is the existence of this microstructural state and attendant local hydrogen concentration that determines the failure mode and pathway.

The observations presented in Figures 8 through 13 begin to determine the connection between the evolved microstructural state and the failure path. In all cases but for failure by microvoid coalescence, the evolved microstructure in the presence of hydrogen was further developed and more complex than in its absence. Collectively, these results support the conclusion that hydrogen-enhanced plasticity mediated processes establish the conditions that promote failure.

\section{DISCUSSION}

The presence of features on hydrogen-generated fracture surfaces that are consistent with plasticity processes has always been recognized. The evidence is irrefutable and is not the subject of contention within the hydrogen embrittlement debate. What has been debated is the role, if any, of this plasticity in hydrogen embrittlement. Is it a consequence of the embrittling event itself and therefore inconsequential as a hydrogen embrittlement mechanism or is it enhanced by the presence of hydrogen and therefore central to hydrogen embrittlement? The decohesion community have utilized plasticity associated with crack advance primarily as a means to generate sufficiently high stresses to attract the levels of hydrogen required to cause the magnitude of the reduction in the bond strength needed to cause failure. ${ }^{[18]}$ However, this approach assumes that the effect of hydrogen on the deformation that has occurred prior to the initiation of failure is inconsequential to the entire embrittlement process. Herein, it is the deformation prior to initiation of failure that is deemed to be deterministic. The following discussion considers how dislocation processes enhanced by hydrogen can influence the fracture pathway and failure mechanism. A detailed discussion is presented for the hydrogeninduced transition in failure pathway from transgranular to intergranular. However, similar arguments could be constructed to account for the other morphological features found on hydrogen-induced fracture surfaces. This point is important as any proposed mechanisms must be able to account for the different features found in close proximity in any given facture surface. In the proposed hydrogen-enhanced plasticity mediated mechanism, the variation in morphologies found on the same fracture surface would reflect local conditions such as the stress state and would take into account that the deformation within each grain evolves at a different rate which imposes additional constraints on neighboring grains. Understanding this collective behavior as well as the self-organization of the microstructure with increasing deformation remains a challenge both in the presence and absence of hydrogen.

To understand the role of plasticity in hydrogeninduced intergranular failure, it is necessary to first digress and discuss how dislocations interact with grain boundaries and how strain is transferred across them in the absence of hydrogen. ${ }^{[106-110]}$ Dislocations impinging on a grain boundary can be accommodated in it. On accommodation, the lattice dislocation can retain its Burgers vector, becoming an extrinsic defect, or it can dissociate into grain boundary dislocations and become an integral part of the new intrinsic structure of the 

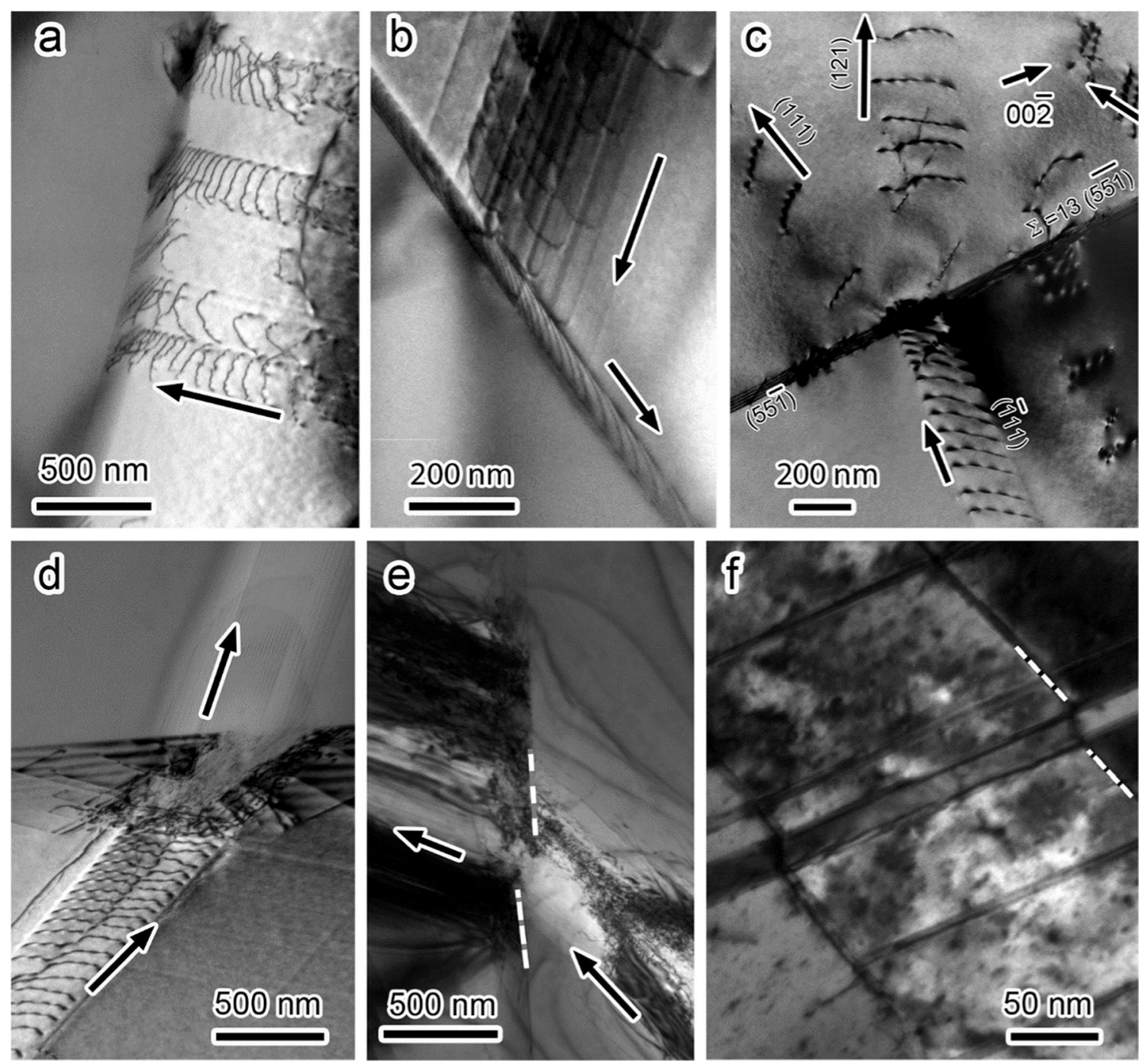

Fig. 14 - Bright-field electron micrographs showing possible interactions of dislocations with grain and interphase boundaries and the attendant changes in the structure of the grain boundary as strain is transferred across it: $(a)$ accommodation of lattice dislocations in a grain boundary in Ti at the point of intersections; $(b)$ cross slip of lattice dislocations onto a grain boundary in stainless steel; $(c)$ slip transfer across a grain boundary in stainless steel; $(d)$ disruption of the grain boundary structure due to slip transfer; $(e)$ displacement of the grain boundary due to slip transfer and $(f)$ rotation of an interphase boundary between $\mathrm{Ag}$ and $\mathrm{Cu}$ layers due to the transmission of deformation twins. The dashed lines indicate the positions of the boundaries. Arrows indicate direction of dislocations motion. a and f adapted from Refs. [111] and [115], and reproduced with permission from Taylor and Francis and Elsevier, respectively.

grain boundary. An example of dislocations being incorporated in a grain boundary in $\mathrm{Ti}$ is shown in Figure 14(a). ${ }^{[111]}$ As seen in this micrograph, numerous dislocations have been accommodated in a grain boundary and remain at the point of impingement. No dislocations have been emitted into the other grain, although there is evidence, in the form of elastic distortions emanating from the grain boundary, of the accommodation of the accumulated strain in the grain boundary. This dislocation content remains following the transmission of strain, as incident dislocations are annihilated or trapped within the grain boundary and new dislocations are generated and emitted from it. This point is important as it establishes that the dislocations emitted from the grain boundary are newly generated. Both the extrinsic and intrinsic defects can be mobile in the grain boundary plane, which will distribute this new content along the grain boundary. The micrograph in Figure 14(b) shows dislocations approaching a grain boundary in 304 stainless steel and essentially cross slipping onto the grain boundary plane. ${ }^{[112]}$ In this type of reaction, there have been questions about the specific location of the conjugate plane, on or adjacent to the grain boundary. ${ }^{[113]}$ In the current effort, it appears that the grain boundary plane served as the conjugate plane. Of course, slip can be transferred across the grain boundary as indicated in Figure 14(c), which shows dislocation transfer across a $\sum 13 a$ grain boundary in 310 stainless steel. ${ }^{[109]}$ With significant slip transmission, there can be changes in the grain boundary structure. Examples of possible effects are shown in Figures 14(d) through (f). The possibilities include disruption of the structure which may be related to the formation of a step on the grain boundary, Figure $14(\mathrm{~d}) \cdot{ }^{[114]}$ Displace- 
ment and rotation of the grain boundary or interphase boundary may occur due to the transmission of dislocations, Figure $14(\mathrm{e}),{ }^{[14]}$ or deformation twins, Figure 14(f), respectively. ${ }^{[15]}$ The dashed lines in these two figures show the location of the boundary. Extending these dashed lines would show the degree of displacement and rotation. It is possible that the micrographs presented in Figures 14(d) and (e) represent the same feature just viewed from different directions. These changes in the grain boundary structure due to slip transfer may have important consequences on the cohesive strength of the grain boundary and the capacity of it to accommodate segregants such as hydrogen. The rotation and displacement of the interface are also important as these would generate irregularities on a fractured grain boundary such as seen in Figures 11(c) and 12(a).

In addition to accommodation of lattice dislocations in the grain boundary causing structural changes in the grain boundary, the transmission event also will cause permanent structural changes. This can be seen by understanding the constraints that dictate which slip system will be activated by the grain boundary to transfer slip. Two local conditions have been considered; the local shear stress generated by the dislocation pile-up that forms against the grain boundary and the strain energy density increase determined by the act of transmission. ${ }^{[107-112,115]}$ The magnitude of the stressfield associated with the dislocation pile-up is related directly to the number of dislocations in it. This imposes a local shear stress on the available slip systems in both grains as well as along the grain boundary. The global stress state as expressed in terms of Schmid factors is not seen as being deterministic in the response of the grain boundary. However, it has been established in FCC and HCP alloys that the local resolved shear stress due to the dislocation pile-up is insufficient by itself to predict which slip system will be activated by the grain boundary to transfer slip across it. ${ }^{[109-112,115]}$ The predicting factor has been found to be the magnitude of the Burgers vector of the grain boundary dislocation generated by the act of slip transmission. This is generated as the incoming and outgoing dislocations are different entities and do not necessarily have the same Burgers vector. The magnitude of the Burgers vector of the residual grain boundary dislocation, $\left|\bar{b}_{\mathrm{r}}^{\mathrm{gb}}\right|$, is determined simply by taking the difference of the magnitudes of the Burgers vectors of the incoming $\left|\bar{b}_{\text {in }}\right|$ and outgoing, $\left|\bar{b}_{\text {out }}\right|$ dislocations, respectively, after they have been expressed in a common frame of reference; i.e., $\left|\bar{b}_{\mathrm{r}}^{\mathrm{gb}}\right|=\left|\bar{b}_{\text {in }}\right|-\left|\bar{b}_{\text {out }}\right|$. This predicting factor could be seen as the grain boundary seeking to minimize the increase in its strain energy density by activating the slip system that minimizes it.

Although the slip systems activated by the grain boundary is determined by this minimization, the magnitude of the resolved shear stress is important as it must be sufficient for the dislocations to move away from the nucleation site into the grain. In pure metals, this condition is readily satisfied, but it has been shown that it plays an increasingly important role in systems in which the grain interior is hardened. For example, in irradiated metals it is found that although the activated system is predicted by minimization of the Burgers vector of the grain boundary dislocation, the resolved shear stress due to the local stress concentration must be of sufficient magnitude to propel the dislocations through the field of irradiation-produced obstacles. $^{[96,98,116]}$ If the local stress is not of sufficient magnitude, an out-of plane displacement of the grain boundary may occur and this may be accompanied by the formation of an incipient crack. Although the grain boundary displacement is attributed to the local stress state, structural unit changes within the grain boundary due to the accommodation of lattice dislocations as well as compositional effects may play important roles. This example is introduced to illustrate that the local stress state, compositional and structural modifications in the grain boundary, as well as other impurity-induced changes in the cohesive strength of the grain boundary have a role to play in establishing the conditions for environment-induced intergranular fracture.

With this knowledge of slip transfer across a grain boundary, a gedanken experiment can be performed to assess the possible impact of hydrogen in causing a transition in failure mode from transgranular to intergranular. Dislocation interactions with grain boundaries and hydrogen effects on dislocations are summarized separately and then in combination in Table I. Essentially, the deformation influenced by hydrogen will increase the rate of generation of dislocation from sources and will enable them to move at lower stress levels. Consequently, the number of dislocation interactions with grain boundaries will increase, which will increase the number of dislocations accommodated in the grain boundary and the number of dislocations piled up against it. The separation distance between dislocations in the pile-up will decrease in the presence of hydrogen. These two effects combine to alter the local state of stress. As hydrogen must be carried with the dislocations, the hydrogen content of the grain boundary will increase because of the accommodation of dislocations in the grain boundary. It would be expected that dislocations glissile in the grain boundary would move at a higher velocity due to the presence of hydrogen; such an effect was reported by Ferreira. ${ }^{[17]}$ As the process of strain transfer does not involve onedislocation-in to one-dislocation-out of the grain boundary or necessarily the same dislocation entity, the net balance of the hydrogen content on the grain boundary is non-zero. The increase in disorder or density of structural imperfections in the grain boundary caused by the act of slip transfer will adjust the capacity of the grain boundary for hydrogen as well as change the properties of the grain boundary. The dynamic hydrogen content of the grain boundary will be controlled not only by the slip transfer process but by the binding energy of hydrogen to the grain boundary, which is greater than at a dislocation. The dislocation interactions with the grain boundary will also result in a change in the microstructure in the vicinity of it, which will modify the local, but not the global stress, state. This thought experiment provides a rational explanation for the role of plasticity on hydrogen-induced intergranular failure although the relative magnitudes of the structural 
Table I. Components of Dislocation Interactions with Grain Boundaries, the Influence of Hydrogen on Dislocation Properties and Combining the Two Effects

Dislocation Interactions with Grain Boundaries

Lattice dislocations accommodated in grain boundary

Trapped dislocations may be extrinsic or become intrinsic

Dislocations may be glissile in the grain boundary

Transfer process involves generating and emitting a new dislocation

Transfer process generates a residual grain boundary dislocation

Disruption/rotation of grain boundary due to significant slip transfer
Influence of Hydrogen on the Behavior of Dislocations

Consequences of Combining the Two hydrogen will increase the density and mobility of dislocations. This will increase the production and trapping rate of dislocations

hydrogen must be transported with the mobile dislocations for the enhanced mobility to operate. This will cause a redistribution of hydrogen to regions of extensive plasticity hydrogen changes the interaction energy between dislocations and other obstacles more dislocation interactions with grain boundaries with more dislocations accommodated in the grain boundary

possible enhancement of dislocation slip along the grain boundary

increased structural disorder in the grain boundary

large disruptive steps formed on the grain boundary

hydrogen deposited on the grain boundary. Hydrogen content accumulated on the grain boundary because of higher binding energy at the grain boundary and strain transfer does not involve one dislocation in and one dislocation out accumulated hydrogen will cause a decrease in cohesive strength of the grain boundary

more dislocations in the pile-up with a smaller equilibrium separation distance. This will cause the local stress field to be enhanced

enhanced slip transfer at lower stresses and compositional grain boundary changes on its cohesive strength remain to be determined. The formation of the steps on the grain boundary facets is now readily explained as a consequence of the slip transmission that occurred prior to the failure event.

The importance of including how the dislocations interact with grain boundaries, the resulting structural and rotational changes and the process of slip transfer itself is also seen in liquid-metal embrittlement with the exception perhaps being the influence of liquid gallium on the response of Al. Here, it has been argued that the structural as well as compositional modifications to the grain boundary play a role and it has been proposed that the local stresses developed through the evolved microstructure also contribute to the grain boundary failure. For example, Luo et al. proposed that complexions in the form of a bi-layer grain boundary phase was responsible for the Bi-induced intergranular failure of Ni. ${ }^{[18]}$ Martin et al. proposed that an additional driving force for intergranular failure in T91, a martensitic alloy, was needed as the reduction in the cohesive strength of the grain boundary due to the presence of the liquid-metal was insufficient by itself. ${ }^{[119]}$ They suggested that the additional driving force was provided by two mechanisms: dislocation interactions with the grain boundary which altered the grain boundary structure and provided more sites for the liquid-metal species, and by the local stress state developed by dislocation structure in the vicinity of the grain boundary. The commonalities in mechanism provide a link between the two environment-induced intergranular failures but the commonality is different than suggested by others. ${ }^{[17]}$

\section{CONCLUSIONS}

1. The assertion made by Beachem ${ }^{[7]}$ related to hydrogen enhancing plasticity processes has been verified experimentally by the in situ TEM straining experiments in a gaseous hydrogen environment and by macroscale mechanical property tests.

2. The assertion made by Beachem ${ }^{[7]}$ that the underlying microstructure is related to the mechanisms and the morphological features on the fracture surface have been established.

3. The local conditions that establish the hydrogen embrittlement fracture mode and pathway are determined by dislocation processes that are enhanced and accelerated by the presence of hydrogen. These processes determine the local distribution of hydrogen as well as the local stress state. The failure mode may be by decohesion, especially for the intergranular failure case, but the determining conditions are driven by hydrogen-enhanced plasticity mediated processes. 
4. Determination of the evolved microstructure especially beneath fracture surfaces via a posteriori analysis of features on a fracture surface can be misleading.

\section{ACKNOWLEDGMENTS}

This manuscript is the results of decades of work by many students and post-docs who were part of the Illinois group. They are too many to name but they know who they are; it was a pleasure to work with all of them. They will understand when this manuscript is dedicated to three of the team: Howard Birnbaum, Teizo Tabata, and Keith Tappin. The work would not have been possible without the support from the Department of Energy, Office of Science, Basic Energy Sciences (Contract No. ACO9-76ERO1198); Department of Energy, Energy Efficiency and Renewable Energy (Grant GO15045); International Institute for Carbon-Neutral Energy Research (WPI-I2CNER), sponsored by the World Premier International Research Center Initiative (WPI), MEXT, Japan, and, finally, the National Science Foundation, through Award No. CMMI-1406462 (IMR).

\section{ELECTRONIC SUPPLEMENTARY MATERIAL}

The online version of this article (doi: 10.1007/s11661-015-2836-1) contains supplementary material, which is available to authorized users.

\section{REFERENCES}

1. W.H. Johnson: Proc. R. S. Lond., 1875, vol. 23, pp. 168-79.

2. D.G. Westlake: J. Nucl. Mater., 1968, vol. 26, pp. 208-16.

3. H.K. Birnbaum: J. Less-Common Met., 1984, vol. 104, pp. 31-41.

4. D.S. Shih, I.M. Robertson, and H.K. Birnbaum: Acta Metall., 1988, vol. 36, pp. 111-24.

5. B.P. Somerday and P. Sofronis: Hydrogen-Materials Interactions, ASM International, Materials Park, OH, 2013.

6. R.P. Gangloff and B.P. Somerday: Gaseous Hydrogen Embrittlement of Materials in Energy Technologies: The Problem, Its Characterisation and Effects on Particular Alloy Classes, Woodhead Publishing Limited, Cambridge, U.K., 2012.

7. C.D. Beachem: Metall. Trans. A, 1972, vol. 3A, pp. 437-51.

8. I.M. Robertson: Eng. Fract. Mech., 2001, vol. 68, pp. 671-92.

9. H.K. Birnbaum and P. Sofronis: Mater. Sci. Eng. A., Struct. Mater., Prop. Microstruct. Process, 1993, vol. A176, pp. 191-202.

10. J.A. Fenske, I.M. Robertson, R. Ayer, M. Hukle, D. Lillig, and B. Newbury: Metall. Trans. A, 2012, vol. 43A, pp. 3011-22.

11. M.L. Martin, I.M. Robertson, and P. Sofronis: Acta Mater., 2011, vol. 59, pp. $3680-87$

12. M.L. Martin, J.A. Fenske, G.S. Liu, P. Sofronis, and I.M. Robertson: Acta Mater., 2011, vol. 59, pp. 1601-06.

13. A. Nagao, M.L. Martin, M. Dadfarnia, P. Sofronis, and I.M. Robertson: Acta Mater., 2014, vol. 74, pp. 244-54.

14. A. Nagao, C.D. Smith, M. Dadfarnia, P. Sofronis, and I.M. Robertson: Acta Mater., 2012, vol. 60, pp. 5182-89.

15. M.L. Martin, B.P. Somerday, R.O. Ritchie, P. Sofronis, and I.M. Robertson: Acta Mater., 2012, vol. 60, pp. 2739-45.

16. S. Wang, M.L. Martin, P. Sofronis, S. Ohnuki, N. Hashimoto, and I.M. Robertson: Acta Mater., 2014, vol. 69, pp. 275-82.
17. S. Lynch: Corros. Rev., 2012, vol. 30, pp. 105-23.

18. W. Gerberich: in Gaseous Hydrogen Embrittlement of Materials in Energy Technologies, R.P. Gangloff and B.P. Somerday, eds., Woodhead Publishing Limited, Cambridge, U.K., 2012, pp. 20946.

19. A. Nagao, M. Dadfarnia, P. Sofronis, and I.M. Robertson: in Encyclopedia of Iron, Steel, and Their Alloys (EISA), R. Colás and G.E. Totten, eds., Taylor \& Francis Group, Abington, Oxon, 2015, vol. in press.

20. C.A. Zapffe and C.E. Sims: Am. Instit. Min. Metall. Eng., 1941, vol. 145 , pp. $225-261$.

21. F.D. Kazinczy: J. Iron Steel Instit., 1954, vol. 177, pp. 85-92.

22. A.S. Tetelman and W.D. Robertson: Acta Metall., 1963, vol. 11, pp. 415-26.

23. N.J. Petch: Philos. Mag., 1956, vol. 1, pp. 331-35.

24. D. Tromans: Acta Metall. Mater., 1994, vol. 42, pp. 2043-49.

25. A.R. Troiano: Trans. Am. Soc. Met., 1960, vol. 52, pp. 54-80.

26. R.A. Oriani: in A Mechanistic Theory of Hydrogen Embrittlement of Steels, Report on the International Conference of the German Bunsen Society for Physical Chemistry and the Julich Nuclear Research Centre 'Hydrogen in Metals', Julich, 1972.

27. C. St John and W.W. Gerberich: Metall. Trans., 1973, vol. 4, pp. 589-94.

28. R.A. Oriani: Corrosion, 1987, vol. 43, pp. 390-97.

29. I.M. Robertson, H.K. Birnbaum, and P. Sofronis: in Dislocations in Solids, J.P. Hirth and L. Kubin, eds., Elsevier, New York, 2009, vol. 19, pp. 249-93.

30. I.M. Robertson and H.K. Birnbaum: Acta Metall., 1986, vol. 34, pp. 353-66.

31. T. Tabata and H.K. Birnbaum: Scripta Metall., 1984, vol. 17, pp. 947-50.

32. M. Nagumo: ISIJ Int., 2001, vol. 41, pp. 590-98.

33. M. Nagumo: Zair. Kankyo, 2007, vol. 56, pp. 343-52.

34. M. Nagumo: Zair. Kankyo, 2007, vol. 56, pp. 382-94.

35. J. Song and W.A. Curtin: Acta Mater., 2011, vol. 59, pp. $1557-$ 69.

36. J. Song and W.A. Curtin: Nat. Mater., 2013, vol. 12, pp. 145-51.

37. J.D. Hobson and J.J. Hewitt: Iron Steel Inst., 1953, vol. 173, pp. $131-40$.

38. D. Eliezer, D.G. Chakrapani, C.J. Altstetter, and E.N. Pugh: Metall. Trans. A, 1979, vol. 10A, pp. 935-41.

39. R. Kirchheim: Int. J. Mater. Res., 2009, vol. 100, pp. 483-87.

40. B. Baranowski: Ber. Bunsenges. Phys. Chem., 1972, vol. 76, pp. $714-24$

41. M.L. Martin, P. Sofronis, I.M. Robertson, T. Awane, and Y. Murakami: Int. J. Fatigue, 2013, vol. 57, pp. 28-36.

42. P. Rozenak, I.M. Robertson, and H.K. Birnbaum: Acta Metall. Mater., 1990, vol. 38, pp. 2031-40.

43. N. Narita, C.J. Altstetter, and H.K. Birnbaum: Metall. Trans. A, 1982, vol. 13 A, p. 1355.

44. D.G. Ulmer and C.J. Altstetter: Acta Metall. Mater., 1993, vol. 41 , pp. $2235-41$.

45. T. Doshida, M. Nakamura, H. Saito, T. Sawada, and K. Takai: Acta Mater., 2013, vol. 61, pp. 7755-66.

46. M. Nagumo: Mater. Sci. Technol., 2004, vol. 20, pp. 940-50.

47. Y. Fukai: J. Alloys Compd., 2003, vol. 356-357, pp. 263-69.

48. C. Skipper, G. Leisk, A. Saigal, D. Matson, and C.S. Marchi: in Effect of internal hydrogen on fatigue strength of type 316 stainless steel, B. Somerday, P. Sofronis, and R. Jones, eds., ASM International, Jackson Hole, WY, 2008, pp. 139-46.

49. M.S. Daw and M.I. Baskes: Phys. Rev. Lett., 1983, vol. 50, pp. 1285-88.

50. W.T. Geng, A.J. Freeman, G.B. Olson, Y. Tateyama, and T. Ohno: Mater. Trans., 2005, vol. 46, pp. 756-60.

51. K.N. Solanki, M.A. Tschopp, M.A. Bhatia, and N.R. Rhodes: Metall. Mater. Trans A, 2013, vol. 44A, pp. 1365-75.

52. S. Wang, M.L. Martin, I.M. Robertson, and P. Sofronis: unpublished research, 2015.

53. S. Plimpton: J. Comput. Phys., 1995, vol. 117, pp. 1-19.

54. S.M. Foiles, M.I. Baskes, and M.S. Daw: Phys. Rev. B, 1986, vol. 33, pp. 7983-91.

55. A. Ramasubramaniam, M. Itakura, and E.A. Carter: Phys. Rev. $B, 2009$, vol. 79, p. 174101 .

56. K.N. Solanki, M.A. Tschopp, M.A. Bhatia, and N.R. Rhodes: Metall. Mater. Trans A, 2013, vol. 44A, pp. 1365-75. 
57. W. Gerberich: in Gaseous Hydrogen Embrittlement of Materials in Energy Technologies, R.P. Gangloff and B.P. Somerday, eds., Woodhead Publishing, Cambridge, U.K. 2012; vol. 1, pp. 209-46.

58. S.M. Ohr: Mater. Sci. Eng., 1985, vol. 72, pp. 1-35.

59. R.M. Thomson: J. Phys. and Chem. Sol., 1987, vol. 48, pp. 965 83.

60. X. Chen, T. Foecke, M. Lii, Y. Katz, and W.W. Gerberich: Eng. Fract. Mech., 1990, vol. 35, pp. 997-1017.

61. D.K. Dewald, T.C. Lee, I.M. Robertson, and H.K. Birnbaum: Metall. Trans. A, 1990, vol. 21A, pp. 2411-17.

62. J.A. Horton and S.M. Ohr: Scripta Metall., 1982, vol. 16, pp. 621-26.

63. S.M. Ohr: Scripta Metall., 1986, vol. 20, pp. 1501-05.

64. D.W. Gross, K. Nygren, G.J. Pataky, J. Kacher, H. Sehitoglu, and I.M. Robertson: Acta Mater., 2013, vol. 61, pp. 5768-78.

65. D.A. Hughes and N. Hansen: Philos. Mag., 2003, vol. 83, pp. 3871-93.

66. D.A. Hughes: Scripta Mater., 2002, vol. 47, pp. 697-703.

67. R.P. Gangloff: in Proceedings of the 2008 International Hydrogen Conference-Effects of Hydrogen on Materials, B. Somerday, P. Sofronis, and R. Jones, eds., ASM International, Jackson Hole, WY, 2009, pp. 1-21.

68. N. Aravas: Private communication, Department of Mechanical Engineering, University of Thessaly, Leoforos Athinon, Pedion Areos, Volos, 2014

69. J.K. Lin and R.A. Oriani: Acta Metall., 1983, vol. 31, pp. 107177.

70. R.A. Oriani and P.H. Josephic: Acta Metall., 1979, vol. 27, pp. 997-1005.

71. R.A. Oriani and P.H. Josephic: Scripta Metall., 1979, vol. 13, pp. 469-71.

72. T.C. Lee, D.K. Dewald, J.A. Eades, I.M. Robertson, and H.K Birnbaum: Rev. Sci. Instrum., 1991, vol. 62, pp. 1438-44.

73. G.M. Bond, I.M. Robertson, and H.K. Birnbaum: Scripta Metall., 1986, vol. 20, pp. 653-58.

74. T. Tabata: unpublished work, deceased, University of Illinois, 1984

75. G.M. Bond, I.M. Robertson, and H.K. Birnbaum: Acta Metall., 1987, vol. 35, pp. 2289-96.

76. G.M. Bond, I.M. Robertson, and H.K. Birnbaum: Acta Metall., 1988, vol. 36, pp. 2193-97.

77. D.P. Abraham and C.J. Altstetter: Metall. Mater. Trans A, 1995, vol. 26A, p. 2859.

78. S. Wang, N. Hashimoto, Y. Wang, and S. Ohnuki: Acta Mater., 2013, vol. 61, pp. 4734-42.

79. E. Sirois and H.K. Birnbaum: Acta Metall. Mater., 1992, vol. 40, pp. 1377-1385.

80. T. Tabata and H.K. Birnbaum: Scripta Metall., 1984, vol. 18, pp. 231-36.

81. T.C. Lee, I.M. Robertson, and H.K. Birnbaum: Acta Metall. 1989, vol. 37, pp. 407-15.

82. G.M. Bond, I.M. Robertson, and H.K. Birnbaum: Acta Metall. 1989, vol. 37, pp. 1407-13.

83. E.P. George and C.T. Liu: in Review of Environmental Effects in Intermetallics, High Temperature Ordered Intermetallic Alloys VI. Symposium, J. Horton, I. Baker, S. Hanada, R.D. Noebe, and D.S. Schwartz, eds., 1995.

84. D.H. Lassila and H.K. Birnbaum: Acta Metall., 1987, vol. 35, pp. 1815-22.

85. P.J. Ferreira, I.M. Robertson, and H.K. Birnbaum: Acta Mater., 1998, vol. 46, pp. 1749-57.

86. P. Sofronis and H.K. Birnbaum: J. Mech. Phys. Sols, 1995, vol. 43, pp. 49-90.

87. J.P. Chateau, D. Delafosse, and T. Magnin: Acta Mater., 2002, vol. 50, pp. 1507-22.
88. J. von Pezold, L. Lymperakis, and J. Neugebeauer: Acta Mater., 2011, vol. 59, pp. 2969-80.

89. J.P. Chateau, D. Delafosse, and T. Magnin: Acta Mater., 2002, vol. 50, pp. $1523-38$

90. P. Novak, R. Yuan, B.P. Somerday, P. Sofronis, and R.O. Ritchie: J. Mech. Phys. Solids, 2010, vol. 58, pp. 206-26.

91. Y. Liang, D.C. Ahn, P. Sofronis, R.H. Dodds, Jr, and D. Bammann: Mech. Mater., 2008, vol. 40, pp. 115-32.

92. M. Dadfarnia, B.P. Somerday, P. Sofronis, I.M. Robertson, and D. Stalheim: J. Press. Vessel Technol., 2009, vol. 131, p. 041404.

93. C.J. McMahon, Jr: Eng. Fract. Mech., 2001, vol. 68, pp. 773-88.

94. T. Neeraj, R. Srinivasan, and J. Li: Acta Mater., 2012, vol. 60, pp. $5160-71$

95. R. Srinivasan and T. Neeraj: JOM, 2014, vol. 66, pp. 1377-82.

96. B. Cui, J. Kacher, M. McMurtrey, G. Was, and I.M. Robertson: Acta Mater., 2014, vol. 65, pp. 150-60.

97. N.M. Ghoniem, S.H. Tong, B.N. Singh, and L.Z. Sun: Philos. Mag. A, 2001, vol. 81, pp. 2743-64.

98. M.D. McMurtrey, G.S. Was, B. Cui, I. Robertson, L. Smith, and D. Farkas: Int. J. Plast, 2014, vol. 56, pp. 219-31.

99. C. Bailat, F. Groschel, and M. Victoria: J. Nucl. Mater., 2000, vol. 276, p. 283

100. N. Baluc, Y. Dai, and M. Victoria: Proceeding of the 20th Riso International Symposium on Materials Science, Roskilde, Denmark, 1999, pp. 245-51.

101. X.Y. Liu, J. Kameda, J.W. Anderegg, S. Takaki, K. Abiko, and C.J. McMahon, Jr: Mater. Sci. Eng. A, 2008, vol. 492, pp. 218 20.

102. C.J. McMahon, Jr: Interface Sci., 2004, vol. 12, pp. 141-46.

103. K.S. Shin and M. Meshii: Acta Metall., 1983, vol. 31, pp. 155966.

104. S. Bechtle, M. Kumar, B.P. Somerday, M.E. Launey, and R.O. Ritchie: Acta Mater., 2009, vol. 57, pp. 4148-57.

105. C. Keller, E. Hug, R. Retoux, and X. Feaugas: Mech. Mater., 2010, vol. 42, pp. 44-54.

106. T.A. Bamford, B. Hardiman, Z. Shen, W.A.T. Clark, and R.H. Wagoner: Scripta Metall., 1986, vol. 20, pp. 253-58.

107. W.A.T. Clark, R.H. Wagoner, Z.Y. Shen, T.C. Lee, I.M. Robertson, and H.K. Birnbaum: Scripta Metall. Mater., 1992, vol. 26, pp. 203-06.

108. Z. Shen, R.H. Wagoner, and W.A.T. Clark: Acta Metall., 1988, vol. 36, pp. 3231-42.

109. T.C. Lee, I.M. Robertson, and H.K. Birnbaum: Metall. Trans. A, 1990, vol. 21A, pp. 2437-2447.

110. T.C. Lee, I.M. Robertson, and H.K. Birnbaum: Philos. Mag. A, 1990, vol. 62, pp. 131-153.

111. J. Kacher and I.M. Robertson: Philos. Mag., 2014, vol. 94, pp. 814-29.

112. J. Kacher and I.M. Robertson: Acta Mater., 2012, vol. 60, pp. $6657-72$.

113. M. Chassagne, M. Legros, and D. Rodney: Acta Mater., 2011, vol. 59, pp. 1456-63.

114. J.P. Kacher: Quasi-four-dimensional characterization of dislocation interactions in $f_{c c}$ and hep systems, University of Illinois, Champaign, IL, 2012.

115. J. Kacher, B. Eftink, B. Cui, and I.M. Robertson: Curr. Opin. Solid State Mater. Sci., 2014, vol. 18, pp. 227-43.

116. B. Cui, M.D. McMurtrey, G.S. Was, and I.M. Robertson: Philos. Mag., 2014, vol. 94, p. 4197.

117. P.J. Ferreira: Hydrogen Effects on Crystal Dislocations and Stacking-Fault Energy, University of Illinois, Urbana, 1996.

118. J. Luo, H. Cheng, K.M. Asl, C.J. Kiely, and M.P. Harmer: Science, 2011, vol. 333, p. 1730.

119. M.L. Martin, T. Auger, D.D. Johnson, and I.M. Robertson: $J$. Nucl. Mater., 2012, vol. 426, pp. 71-77. 